\title{
RESEARCH
}

Open Access

\section{Overcoming bioprocess bottlenecks in the large-scale expansion of high-quality hiPSC aggregates in vertical-wheel stirred suspension bioreactors}

Breanna S. Borys ${ }^{1,2,3+}$, Tiffany Dang ${ }^{1,2,3+}$, Tania So ${ }^{1,3}$, Leili Rohani ${ }^{4}$, Tamas Revay ${ }^{5}$, Tylor Walsh ${ }^{1,2,3}$,

Madalynn Thompson ${ }^{4}$, Bob Argiropoulos ${ }^{5}$, Derrick E. Rancourt ${ }^{4}$, Sunghoon Jung ${ }^{6}$, Yas Hashimura ${ }^{6}$, Brian Lee ${ }^{6}$ and Michael S. Kallos ${ }^{1,2,3^{*}}$ (D)

\begin{abstract}
Background: Human induced pluripotent stem cells (hiPSCs) hold enormous promise in accelerating breakthroughs in understanding human development, drug screening, disease modeling, and cell and gene therapies. Their potential, however, has been bottlenecked in a mostly laboratory setting due to bioprocess challenges in the scale-up of large quantities of high-quality cells for clinical and manufacturing purposes. While several studies have investigated the production of hiPSCs in bioreactors, the use of conventional horizontal-impeller, paddle, and rocking-wave mixing mechanisms have demonstrated unfavorable hydrodynamic environments for hiPSC growth and quality maintenance. This study focused on using computational fluid dynamics (CFD) modeling to aid in characterizing and optimizing the use of vertical-wheel bioreactors for hiPSC production.

Methods: The vertical-wheel bioreactor was modeled with CFD simulation software Fluent at agitation rates between 20 and $100 \mathrm{rpm}$. These models produced fluid flow patterns that mapped out a hydrodynamic environment to guide in the development of hiPSC inoculation and in-vessel aggregate dissociation protocols. The effect of single-cell inoculation on aggregate formation and growth was tested at select CFD-modeled agitation rates and feeding regimes in the vertical-wheel bioreactor. An in-vessel dissociation protocol was developed through the testing of various proteolytic enzymes and agitation exposure times.

(Continued on next page)
\end{abstract}

\footnotetext{
* Correspondence: mskallos@ucalgary.ca

${ }^{\dagger}$ Breanna S. Borys and Tiffany Dang are co-first authors.

'Pharmaceutical Production Research Facility, Schulich School of Engineering, University of Calgary, 2500 University Dr. NW, Calgary, AB T2N 1N4, Canada

${ }^{2}$ Biomedical Engineering Graduate Program, University of Calgary, 2500 University Dr. NW, Calgary, AB T2N 1N4, Canada

Full list of author information is available at the end of the article
}

(C) The Author(s). 2021 Open Access This article is licensed under a Creative Commons Attribution 4.0 International License, which permits use, sharing, adaptation, distribution and reproduction in any medium or format, as long as you give appropriate credit to the original author(s) and the source, provide a link to the Creative Commons licence, and indicate if changes were made. The images or other third party material in this article are included in the article's Creative Commons licence, unless indicated otherwise in a credit line to the material. If material is not included in the article's Creative Commons licence and your intended use is not permitted by statutory regulation or exceeds the permitted use, you will need to obtain permission directly from the copyright holder. To view a copy of this licence, visit http://creativecommons.org/licenses/by/4.0/. The Creative Commons Public Domain Dedication waiver (http://creativecommons.org/publicdomain/zero/1.0/) applies to the data made available in this article, unless otherwise stated in a credit line to the data. 
(Continued from previous page)

Results: CFD modeling demonstrated the unique flow pattern and homogeneous distribution of hydrodynamic forces produced in the vertical-wheel bioreactor, making it the opportune environment for systematic bioprocess optimization of hiPSC expansion. We developed a scalable, single-cell inoculation protocol for the culture of hiPSCs as aggregates in vertical-wheel bioreactors, achieving over 30-fold expansion in 6 days without sacrificing cell quality. We have also provided the first published protocol for in-vessel hiPSC aggregate dissociation, permitting the entire bioreactor volume to be harvested into single cells for serial passaging into larger scale reactors. Importantly, the cells harvested and re-inoculated into scaled-up vertical-wheel bioreactors not only maintained consistent growth kinetics, they maintained a normal karyotype and pluripotent characterization and function.

Conclusions: Taken together, these protocols provide a feasible solution for the culture of high-quality hiPSCs at a clinical and manufacturing scale by overcoming some of the major documented bioprocess bottlenecks.

Keywords: Induced pluripotent stem cells, Vertical-wheel bioreactor, Computational fluid dynamics, Scale-up, Single cell, Harvest, Serial passage

\section{Introduction}

Engineering approaches to understand and control stem cell behavior are needed to address major technology bottlenecks in bioprocessing knowledge [1-3]. Pluripotent stem cells have a high in vitro proliferation capacity and maintain the ability to differentiate into all three germ layers of the human body, making them an ideal cell platform for biomedical engineering applications [4-8]. With the ability to overcome ethical challenges associated with traditional embryonic cell sources, human induced pluripotent stem cells (hiPSCs) are of particular interest in research, clinical and manufacturing markets. Despite the demand for hiPSC production, a lack of standardized protocols and challenges with large-scale expansion to meet relevant cell quantities have prevented many advances in the field [9-11]. The number of high-quality cells required for treatment ranges from $10^{9}$ to $10^{12}$ depending on the therapeutic target, with therapeutic efficacy directly correlating to cell dose [12]. Bioreactors are the method of choice for controlled cell expansion, offering advantages including reduced labor and operating costs, greater cellular homogeneity, and more efficient cell expansion and differentiation capabilities compared to laboratoryscaled static culture flasks [13]. A drawback to the bioreactor environment is the potential for cells to be damaged by high shear stress which can tear apart cells and cell aggregates, resulting in lower cell quality and cell yield [14]. While several studies have investigated the production of hiPSCs in bioreactors, the use of conventional horizontal-impeller, paddle, and rocking-wave mixing mechanisms has demonstrated unfavorable hydrodynamic environments for hiPSC growth and quality maintenance. Current studies achieve only moderate cell fold increases during the expansion phase, and there exists a lack of scalable protocols for the inoculation and harvesting phases [15-21].

A major hurdle for hiPSC expansion in bioreactors has been defining a scalable cell inoculation protocol that successfully maintains cell growth rates without sacrificing cell quality. Single-cell enzymatic dissociation of hPSCs has been reported to result in a drastic loss of cell viability. Thus, hPSCs are generally plated as clumps and grown as colonies or aggregates [11]. Even with a static growth platform, non-colony-type monolayers have resulted in low cell production and reported chromosomal abnormalities and potential selection pressure for mutated cells [22, 23]. While clump seeding has been widely reported as an inoculation strategy for bioreactor culture [24-30], it produces a bottleneck in scalability. It is also difficult to control the clump size, resulting in heterogeneity of bioreactor aggregates leading to increased apoptosis and spontaneous differentiation [11, 24]. To avoid the formation of large aggregates prone to necrotic centers, optimal cell inoculation methods and passaging schedules should be determined. Single-cell inoculation methods have been tested with traditional bioreactor models; however, studies have required large cell seeding densities which resulted in low cell production [11].

Downstream hiPSC bioreactor operations also lack scalable protocols. Harvesting is a critical step in serial passaging and recovery of the final cell product [9], but excessive shear during the harvesting process can alter cell phenotype [31]. Few studies have investigated potential methods for full bioreactor harvesting of hiPSC aggregate culture. Publications only collect small $(1-5 \mathrm{~mL})$ aggregate samples from the bioreactor to dissociate for cell counts using enzymatic and mechanical dissociation techniques which cannot be translated to harvesting $[9,10,32]$.

In this study, we utilized computational fluid dynamics (CFD) modeling to map out the hydrodynamic environment of a vertical-wheel bioreactor produced by PBS Biotech, Ltd. Hydrodynamic forces are difficult to study empirically due to confounding dynamic variables present at any given instant [33]. CFD modeling can be applied to understand hydrodynamics in stirred 
suspension bioreactors. This in turn affects cell viability, proliferation, pluripotency, and differentiation. The CFD model allowed us to confirm that the verticalwheel platform uniquely combines radial and axial flow components producing more uniform distributions of hydrodynamic forces and better scalability compared to traditional bioreactor geometries [34, 35]. We hypothesized that the hydrodynamic environment of the vertical-wheel bioreactor would make it the ideal platform for protocol development to overcome challenges in hiPSC bioprocess scale-up. Table 1 highlights the major geometrical differences and known advantages of the proposed vertical-wheel bioreactor compared to traditional horizontal-blade bioreactors [36]. By adjusting the vertical-wheel operating parameters, we showed success in single-cell hiPSC inoculation resulting in over 30 -fold expansion in 6 days. This could not be mimicked in traditional horizontal-blade bioreactors which produced heterogenous cell aggregates and minimal cell expansion when seeded as single cells. Using enzymatic dissociation within the agitated vertical-wheel bioreactor, we designed a harvesting protocol capable of achieving a recovery efficiency of over 95\%. The optimized inoculation and harvesting protocols were combined in a serial passage and scale-up study that showed reproducible hiPSC growth that maintains a normal karyotype, a positive expression of pluripotency markers, and the functional ability to differentiate into all three germ layers.

\section{Materials and methods}

\section{Computational fluid dynamics modeling}

The 100-mL vertical-wheel bioreactor (PBS Biotech, Camarillo, USA) was modeled with CFD simulation software Fluent 16.2 (ANSYS Inc. Cannonsburg, USA). Fluent employs a finite volume formulation to numerically solve CFD models. Virtual geometry models of the reactor were created using the computer-aided design (CAD) software AutoCAD and imported into the meshing software ICEM ANSYS. The reactor geometry was discretized using tetrahedral elements and boundary conditions were prescribed at different surfaces. Wall boundary conditions were applied to the vessel wall and impeller, indicating regions of zero normal velocity and no tangential velocity relative to the wall (no slip condition). The liquid surface was modeled with a free surface boundary condition, defining a fixed, frictionless wall with no tangential velocity restrictions, and zero normal velocity. The impeller rotation was implemented using a moving reference frame with an interface boundary condition used between the rotating and stationary domains.

A semi-implicit method for pressure-linked equations (SIMPLE) algorithm was used to numerically solve the realizable k-epsilon Navier-Stokes equations. The kepsilon model is one of the most widely used turbulent models for simulating the hydrodynamic environment in suspension bioreactors [37-39] and has been validated with particle image velocimetry (PIV) [40]. Navier-Stokes

Table 1 The major geometrical differences and known advantages of the proposed vertical-wheel bioreactor compared to traditional horizontal-blade bioreactors

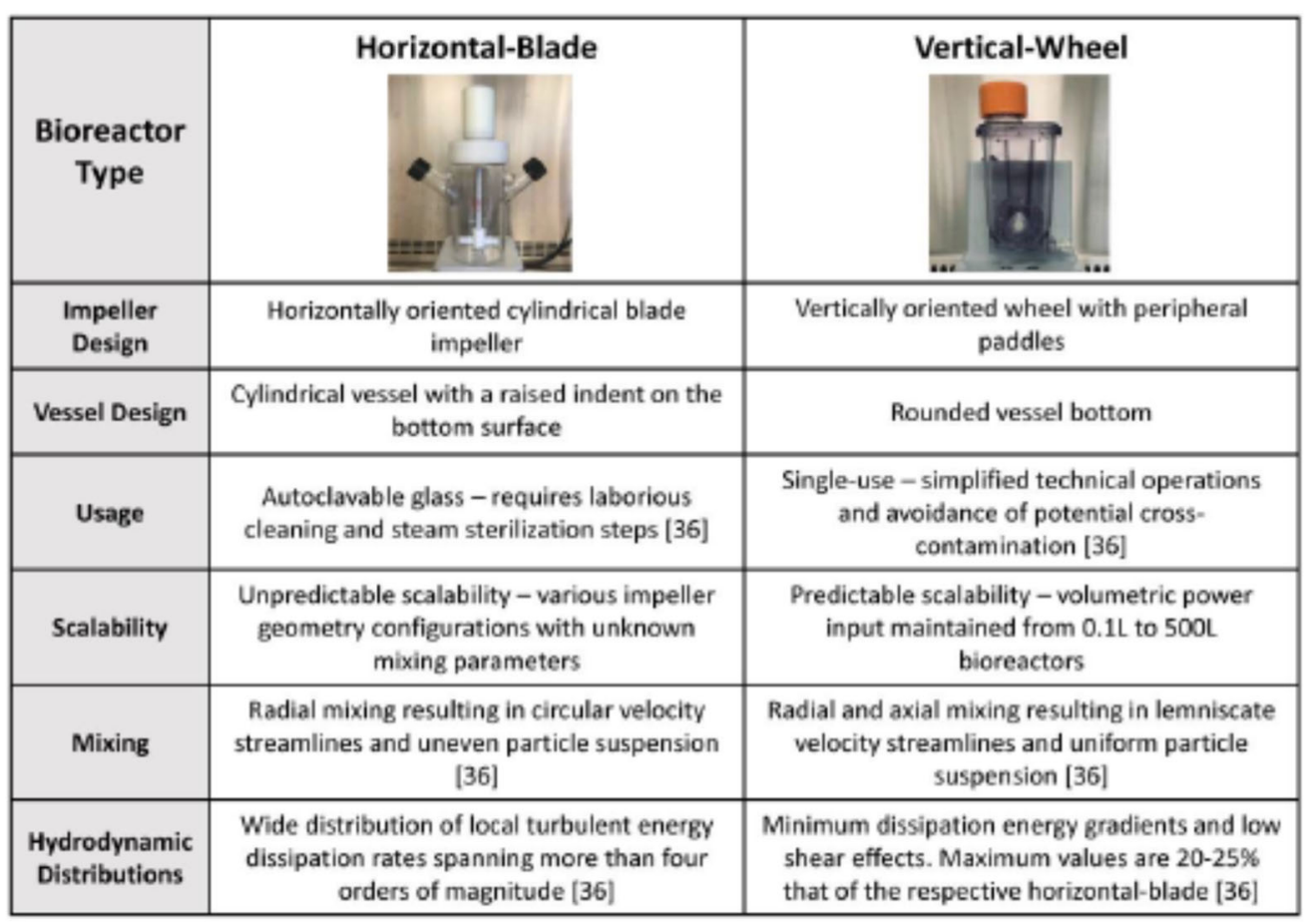


utilizes Eqs. 1 and 2 to represent the transport of mass and momentum through viscous fluid:

$$
\begin{aligned}
& \frac{\partial \rho}{\partial t}+\nabla \cdot(\rho u)=0 \\
& \frac{\partial \rho u}{\partial t}+\nabla(\rho u \otimes u)=-\nabla P+\mu \nabla^{2} u+\rho g
\end{aligned}
$$

In the above equations, $\rho$ is the density, $u$ is the Cartesian velocity vector, $t$ is time, $P$ is pressure, $\mu$ is viscosity, and $g$ is the gravity vector. Water at $37^{\circ} \mathrm{C}$ with a density of $0.993 \mathrm{~g} / \mathrm{cm}^{3}$, a dynamic viscosity of $7.01 \times 10^{-4} \mathrm{~kg} /$ (m s), and kinematic viscosity of $0.696 \mathrm{~mm}^{2} / \mathrm{s}$ was used to simulate the fluid inside the reactor. In order to represent turbulence in the system, the realizable k-epsilon model implements two additional transport equations to account for kinetic energy and energy dissipation rate.

All equations were discretized using a second-order upwind scheme. Models were generated at agitation rates of $20,40,60,80$, and $100 \mathrm{rpm}$, each run for a flow time of $5 \mathrm{~s}$ with time steps chosen to ensure the Courant-Friedrich-Lewy (CFL) number remained below 1. This guaranteed that the fluid element would cross from one end of the mesh element to the other in a single time step. Post processing was performed on each simulated model to derive velocity, shear stress (force acting on a surface parallel to the plane in which it lies), and energy dissipation rate (energy lost by viscous forces) distributions.

\section{Static culture of hiPSCs}

hiPSC line 4YA, passage numbers 40 to 45 , were used for all experiments in this study. These cells were obtained from Dr. James Ellis' laboratory at the University of Toronto (Toronto, Canada). For expansion prior to inoculation in bioreactor culture, hiPSCs were grown in T-75 flasks (Cat\#156599, Thermo Scientific) maintained under standard culture conditions $\left(37^{\circ} \mathrm{C}\right.$ and $\left.5 \% \mathrm{CO}_{2}\right)$. Flasks were coated with feeder-free substrate hESCqualified Matrigel (Cat\#354277, Corning Life Sciences) in DMEM/Hams F-12 (Cat\#10-090-CV, Corning Life Sciences) for $2 \mathrm{~h}$ at room temperature. The cells were inoculated into T-75 flasks at a density of 15,000 cells $/ \mathrm{cm}^{2}$ with $15 \mathrm{~mL} /$ flask mTeSR1 medium (Cat\#85851, STEM CELL Technologies) supplemented with $10 \mu \mathrm{M}$ Y-27632 (Cat\#72304, STEMCELL Technologies). Daily medium replacements were carried out, excluding the addition of Y-27632. When approximately $80 \%$ confluency was reached (3-4 days), hiPSCs from static were passaged. Static cultures were washed once with $\mathrm{Ca}^{2+}$ - and $\mathrm{Mg}^{2+}$ free phosphate buffer solution (PBS) and treated with 5 mL/flask 0.5 mM EDTA.4Na Accutase (Cat\#07920, STEM CELL Technologies) supplemented with $10 \mu \mathrm{M}$ Y-27632 and incubated at $37^{\circ} \mathrm{C}$ for $5 \mathrm{~min}$. Medium supplemented with $10 \mu \mathrm{M}$ Y-27632 was added at a 1:1 ratio of Accutase to dilute the enzyme. The culture was then transferred to a conical tube to be centrifuged at $300 \mathrm{~g}$ for $5 \mathrm{~min}$. The supernatant was discarded, and the cell pellet was resuspended in a medium supplemented with $10 \mu \mathrm{M} \mathrm{Y-27632}$ to be counted and inoculated into bioreactor culture.

\section{Suspension culture of hiPSCs}

This study used 100-mL working volume horizontalblade, glass bioreactors (Corning Style Spinner Flask, NDS Technologies Inc.) and $100-\mathrm{mL}$ and $500-\mathrm{mL}$ working volume single-use, vertical-wheel bioreactors (PBS Biotech Ltd). Constant mixing was maintained at agitations rates of 40,60 , and $80 \mathrm{rpm}$ in standard culture conditions of $37^{\circ} \mathrm{C}$ and $5 \% \mathrm{CO}_{2}$. hiPSCs were inoculated at a density of 20,000 cells $/ \mathrm{mL}$ and cultured at maximum working volumes $(100 \mathrm{~mL}$ and $500 \mathrm{~mL})$ of mTeSR1 medium supplemented with $10 \mu \mathrm{M}$ Y-27632. Experiments utilized either single-cell or pre-formed aggregate inoculation methods. Bioprocess parameters, including the selected low cell seeding density and protocol used to pre-form aggregated cell clumps, were adopted from a previous study as a positive control to compare single-cell inoculation in the vertical-wheel bioreactor [41]. When inoculated as single cells, hiPSCs removed from static culture were counted and added directly into the agitated bioreactor culture. When inoculated as pre-formed aggregates, hiPSCs removed from static culture were counted and inoculated into 6-well suspension culture plates (Cat\#657-185, Greiner CELL STAR) at a concentration of 200,000 cells $/ \mathrm{cm}^{2}$ in 2.0 $\mathrm{mL} /$ well mTeSR1 supplemented with Y-27632. Wells were left in the incubator for $4 \mathrm{~h}$ to pre-form aggregated cell clumps which were then inoculated into the bioreactor.

Experiments studying the effects of nutrient availability in $100 \mathrm{~mL}$ and $500 \mathrm{~mL}$ fed-batch conditions involved a $50 \%$ mTeSR1 medium exchange (excluding Y-27632) on day 4 of culture. To perform the medium exchange, bioreactors were brought under a laminar flow hood where cell aggregates settled for $5 \mathrm{~min}$. Media were aspirated from the top surface of the bioreactor and added to a conical tube to be centrifuged at $300 \mathrm{~g}$ for $3 \mathrm{~min}$. Media from the conical tube were discarded, and the remaining cell pellet was resuspended in fresh mTeSR1 media to be added back into the bioreactor.

\section{Cell counts and aggregate sizing}

To study the growth kinetics of hiPSCs in bioreactor culture, daily samples were taken with cell counts performed in duplicates. Samples of $1.0-5.0 \mathrm{~mL}$ were removed using a serological pipette during bioreactor agitation to minimize settling of the aggregates. The samples were centrifuged at $300 \mathrm{~g}$ for $5 \mathrm{~min}$. The supernatant 
was discarded, and the cell pellet was resuspended in $1.0 \mathrm{~mL}$ of Accutase and left in a $37^{\circ} \mathrm{C}$ water bath for 5-7 min. The cell solution was then gently pipetted 3 times followed by the addition of $1.0 \mathrm{~mL}$ of the medium used to dilute the enzyme. The sample was centrifuged at $500 \mathrm{~g}$ for $5 \mathrm{~min}$, the supernatant was discarded, and the cell pellet was resuspended in $0.5-1.0 \mathrm{~mL}$ medium. Two, $200 \mu \mathrm{L}$ aliquots were taken from each cell sample for viable cell counts using the NucleoCounter NC-200 (ChemoMetec, Denmark), an automated cassette counter which analyzes samples stained with fluorescent dyes Acridine Orange and DAPI. These counts were used to generate cell growth curves and calculate fold expansion utilizing Eq. 3:

$$
\text { Fold expansion }=\frac{X_{2}}{X_{1}}
$$

where $X_{1}$ and $X_{2}$ are the viable cell densities (cells $/ \mathrm{mL}$ ) at the beginning and end of the culture passage.

To determine average aggregate size and size distributions, $1.5-\mathrm{mL}$ samples were removed using a serological pipette from the bioreactors and added into 12-well plates for visualization. Images were taken using a Zeiss Axiovert 25 microscope (Carl Zeiss) with AxioVision software used for measurements. Aggregates were defined as multi-cellular spheroids with a diameter greater than $50 \mu \mathrm{m}$. The diameter for each aggregate was determined by taking the average of the greatest length across the aggregate and the length perpendicular to the greatest length. A minimum of 100 aggregates were sized per condition.

\section{Bioreactor harvesting}

An in-vessel harvest protocol was developed through the testing of various proteolytic enzymes and agitation exposure times. Proteolytic enzymes tested were Accutase (Cat\#07922, STEMCELL Technologies), TrypLE (Cat\# 12605028, ThermoFisher), and $0.05 \%$ Trypsin-EDTA (Cat\#25300062, ThermoFisher). The bioreactor was brought under the laminar flow hood where aggregates settled for $5 \mathrm{~min}$. Media from the bioreactor were aspirated into conical tubes, leaving approximately $3 \mathrm{~mL}$ of aggregate culture in the bioreactor. Conical tubes were centrifuged at $300 \mathrm{~g}$ for $5 \mathrm{~min}$. Media from the conical tubes were discarded, and the remaining cell pellets were resuspended in $20 \mathrm{~mL}$ of proteolytic enzyme with $10 \mu \mathrm{M}$ Y-27632 and added back into the bioreactor aggregate culture. The bioreactor was then placed back in the incubator $\left(37^{\circ} \mathrm{C}, 5 \% \mathrm{CO}_{2}\right)$ and agitated at $80 \mathrm{rpm}$. Every $5 \mathrm{~min}$, for a total of $30 \mathrm{~min}$, the bioreactor was quickly brought under the laminar flow hood where $200-\mu \mathrm{L}$ samples were removed for cell counts and phasecontrast imaging. Cell counts were performed using the NucleoCounter NC-200 to obtain a viable cell density and a percent of cells in aggregates (defined by the instrument as a cluster of 5 or more cells). To calculate the dissociation efficiency at each time point, Eq. 4 was used:

$$
\text { Dissociation Efficiency }=\frac{A}{B} \times 100-\text { cells in aggregates }
$$

where variables $A$ and $B$ are total cell numbers in the reactor before and after the harvesting procedure. The total cells in the reactor prior to harvesting were calculated through Eq. 5:

$$
A=\text { Ave } \frac{\text { cell }}{\mathrm{mL}} \text { sample count } \times \text { reactor volume predissociation }
$$

where the average sample count was determined through bioreactor cell samples $(1.0 \mathrm{~mL})$ dissociated via traditionally counting methods described above. The reactor volume predissociation was the sum of the media transferred to conical tubes and the remaining aggregate culture in the bioreactor (approximately $3 \mathrm{~mL}$ ). Total cells in the reactor after the harvesting procedure was calculated through Eq. 6:

$$
B=\text { Ave } \frac{\text { cell }}{\mathrm{mL}} \text { sample count } \times \text { reactor volume post dissociation }
$$

where the average sample count was determined from the $200-\mu \mathrm{L}$ samples taken directly from the bioreactor during the harvesting procedure. The reactor volume post dissociation was the sum of the proteolytic enzyme volume added to the bioreactor $(20 \mathrm{~mL})$ and the remaining aggregate culture in the bioreactor prior to harvesting (approximately $3 \mathrm{~mL}$ ).

\section{Karyotyping}

Samples of bioreactor-generated aggregates were incubated in 10-mL bioreactors in medium supplemented with $0.1 \mu \mathrm{g} / \mathrm{mL}$ KaryoMax Colcemid (Cat\#15212012, ThermoScientific) for $4 \mathrm{~h}$. The aggregates were then enzymatically dissociated as previously described. Single cells were collected by centrifugation, suspended in $0.075 \mathrm{M} \mathrm{KCl}$ hypotonic solution (Cat\#P217-500, Fischer Scientific), and incubated at $37^{\circ} \mathrm{C}$ for $25 \mathrm{~min}$. Cells were then fixed with 3:1 methanol to acetic acid solution (Cat\#A412-4, Fisher Scientific, Cat\#AX0073, EMD), and chromosome preparations were GTG-banded using standard cytogenetic techniques. Karyograms were analyzed according to the ISCN standards at $\sim 450$ band resolution using the Ikaros karyotyping system (Metasystems). 


\section{Aggregate immunocytochemistry}

Aggregate samples containing 1E6 cells were removed from the bioreactor culture and added into microcentrifuge tubes (Cat\#10011-724, VWR). Aggregates were rinsed twice with PBS and resuspended in $0.5 \mathrm{~mL}$ of fixation buffer (Cat\#FC001, R\&D Systems) to be incubated for $1 \mathrm{~h}$ at room temperature. Aggregate samples were then rinsed twice with PBS and resuspended in 200- $\mu \mathrm{L}$ permeabilization buffer (Cat\#FC005, R\&D Systems) with $1 \mu \mathrm{g} / 10^{6}$ cells antibody stain and $1 \mu \mathrm{M} / 10^{6}$ cells nuclei stain and incubated for $3 \mathrm{~h}$ at room temperature. Conjugated antibody stains for SSEA-4 (Cat\#FAB1435F, R\&D Systems), TRA-1-60 (Cat\# FAB4770P, R\&D Systems), and Nanog (Cat\#MABD24A4, Millipore Sigma) were used along with the nuclei stain To-Pro-3 Iodide Nucleic Acid Stain (Cat\#T3605, Thermo Fisher). Cells were then rinsed twice with PBS and imaged using a Carl Zeiss Laser Scanning Microscope 700 with lasers at $488 \mathrm{~nm}$ and $639 \mathrm{~nm}$ and corresponding filter sets.

\section{Tri-lineage differentiation}

Bioreactor-cultured hiPSC aggregates were differentiated into cardiomyocytes, hepatocytes, and neural rosettes using the previously published protocols [42-44]. The aggregates were collected on day 12 post-inoculation and were either dissociated into single cells as described in the "Materials and methods" section or directly plated as aggregates for in vitro differentiation. For both cardiomyocyte and hepatocyte differentiation, hiPSCs were seeded at a density of 2E5 cells/plate on Matrigel-coated FluoroDish Cell Culture Dish plates (Cat\#FD35-100, World Precision Instrument) containing mTeSR1 supplemented with Y-27632 and cultured to 80-90\% confluency before undergoing differentiation [42, 43]. Mature cardiomyocytes and hepatocytes at day 20 of differentiation were used for the analysis. For neural rosette differentiation, hiPSC aggregates were cultured on poly-L-ornithine (Cat\#A-004-C, Sigma Aldrich)coated FluoroDish cell culture dish plates in DMEM/ F12 medium supplemented with 5\% KnockOut serum replacement (Cat\# 10828010, Thermo Fisher Scientific), $0.1 \mathrm{mM}$ non-essential amino acids (Cat\# 11140050, Thermo Fisher Scientific), $0.1 \mathrm{mM}$ 2-mercaptoethanol (Cat\#21985023, Thermo Fisher Scientific), and 1\% penicillin-streptomycin (Cat\#15140122, Thermo Fisher Scientific) for 4 days. Further, the aggregates were transferred onto Matrigel-coated plates in Neurobasal ${ }^{\mathrm{mm}}$ Medium (Cat\#21103049, Thermo Fisher Scientific) supplemented with B27 without retinoic acid (Cat\#12587010, Thermo Fisher Scientific), N2 supplement (Cat\#17502048, Thermo Fisher Scientific), 0.005\% bovine serum albumin (Cat\#15260037, Thermo Fisher Scientific), and $1 \mathrm{mM}$ sodium pyruvate (Cat\#11360-070, Thermo Fisher Scientific) for an additional 5 days before analysis. Differentiated cardiomyocytes and hepatocytes were analyzed by whole-mount immunostaining and confocal imaging using Cardiac Troponin T antibody (Cat\#MA5-12960, $5 \mu \mathrm{g} / \mathrm{mL}$, Thermo Fisher Scientific), HNF-4-alpha antibody (Cat\#ab92378, 1:100, Abcam), and CYP3A4 antibody (Cat\# MA5-17064, 1:200, Thermo Fisher Scientific). Neural rosettes were analyzed using Pax-6 (Cat\# PRB278P, 1:100, BioLegend) and Tubulin $\beta 3$ (TUBB3) (Cat\#801202, $1 \mu \mathrm{g} / \mathrm{mL}$, BioLegend) antibodies.

\section{RNA isolation and reverse transcription (RT) quantitative} (q) polymerase chain reaction (PCR) (RT-qPCR)

hiPSC aggregates were collected on day 6 and day 12 post-inoculation and used for RNA isolation. Total RNA was extracted using PureLink $^{\mathrm{Tm}}$ RNA Mini Kit (Cat\#12183018A, Thermo Fisher Scientific) according to the manufacturer protocol, followed by DNAse I digestion using DNAse I Amplification Grade (Cat\#18068015, Thermo Fisher Scientific). Next, 500 ng RNA was used for cDNA synthesis using Superscript ${ }^{\circ}$ IV Reverse Transcriptase (Cat\#18090010, Thermo Fisher Scientific) and $50 \mu \mathrm{M}$ Oligo (dT)20 Primer (Cat\#18418020, Thermo Fisher Scientific) according to the manufacturer's instructions. To quantitate transcripts, the subsequent RT-qPCR gene expression analysis was performed on Applied Biosystems (Thermo Fisher Scientific) using Fast SYBR ${ }^{\mathrm{m}}$ Green Master Mix (Cat\#4385612, Thermo Fisher Scientific). For each sample, relative mRNA expression was quantified relative to the housekeeping gene GAPDH and was normalized to static cultured hiPSC level $(=1)$. The relative quantification (RQ) was completed based on comparative $C_{T}$ $\left(\Delta \Delta \mathrm{C}_{\mathrm{T}}\right)$ through the $2^{-\Delta \Delta C \mathrm{CT}}$ method. The gene expression results are shown as relative mRNA expression (RQ) to static cultured hiPSCs $(R Q=1)$. At least two technical and three biological replicates were assayed for all quantitative RT-PCR reactions. Pluripotency-associated genes, Oct-4, Sox2, Nanog, Klf4, and Rex1, were used for RT-qPCR. The primer sequences for SYBR Green probe are listed in Supplementary Table 1.

\section{Statistics}

Statistical analysis was done using GraphPad Prism (v6.0). A one-way ANOVA followed by Dunnett multiple comparison test was used for all growth curve and aggregate size comparisons. Cell samples were collected from $n=4$ stirred suspension bioreactors at each condition. The $P$ values were set at 0.05 , and all graphs are presented with $a \pm$ standard error of the mean (SEM). A one-way analysis of variance (ANOVA) followed by Tukey's multiple comparison test was used for RT-qPCR for statistical analysis. The significance was set at $P<$ 0.05 using GraphPad Prism. 


\section{Results}

\section{Vertical-wheel bioreactor CFD modeling}

To investigate the hydrodynamic environment, the vertical-wheel bioreactor, geometrically outlined in Fig. 1a, was modeled at agitation rates between 20 and $100 \mathrm{rpm}$. Figure 1b displays the change in volume average hydrodynamic variables (velocity, shear stress, and energy dissipation rate) from when the model was initiated through $5 \mathrm{~s}$ of flow time. Steady state is reached between 2 and $3 \mathrm{~s}$ for all tested agitations, evident by the plateau in measured values. The exception being 100 $\mathrm{rpm}$, where the volume average energy dissipation rate continues to fluctuate between $3.7 \mathrm{E}-3 \mathrm{~m}^{2} / \mathrm{s}^{3}$ and $4.7 \mathrm{E}-3$ $\mathrm{m}^{2} / \mathrm{s}^{3}$ due to an increase in turbulent energy. Both volume average velocity and volume average shear stress increase in a linear fashion with respect to agitation rate. Conversely, volume average energy dissipation rate increases exponentially with respect to agitation rate. It is evident from the vertical slices in the bioreactor (Fig. 1c) that at a lower operating condition, $40 \mathrm{rpm}$, hydrodynamic forces within the reactor are very consistent. The distribution in energy dissipation rate throughout the reactor height is particularly narrow, with no noticeable changes within the rotating domain at the given colorimetric scale. At a higher operating condition, 100 rpm, hydrodynamic forces show an increase in variability within the reactor volume, with much greater forces acting around the impeller blades. The difference in maximum force values, which are often calculated to keep constant in scale-up, are orders of magnitude higher than the volume average values. At $100 \mathrm{rpm}$, for instance, the maximum energy dissipation rate is $8.9 \mathrm{E}-1$ $\mathrm{m}^{2} / \mathrm{s}^{3}$ whereas the volume average energy dissipation rate is $4.2 \mathrm{E}-3 \mathrm{~m}^{2} / \mathrm{s}^{3}$. What is particularly interesting is the CFD generated flow patterns within the verticalwheel bioreactor, shown in Fig. 2. The velocity streamlines in the vertical-wheel bioreactor display a lemniscate (figure-eight) profile. Unlike traditional horizontalimpeller bioreactors, the fluid in the vertical-wheel reactor moves throughout the entire liquid width and height. The fluid streamlines weave between the pitched wheel blades with increased velocity corresponding to an increase in agitation.

\section{Single-cell bioreactor inoculation}

To first investigate the potential of single-cell inoculation, hiPSCs were seeded into $100-\mathrm{mL}$ working volume horizontal-blade and vertical-wheel bioreactors operated at $40 \mathrm{rpm}, 60 \mathrm{rpm}$, and $80 \mathrm{rpm}$ for 6 days of batch culture. As is evident from the growth curve and foldexpansion data (Fig. 3a), single-cell inoculation of hiPSCs in the vertical-wheel reactor was quite successful, reaching a maximum expansion of $16.7 \pm 1.1$-fold at 40 rpm. In contrast, fold expansion in the horizontal-blade bioreactor was minimal, reaching a maximum of $6.3 \pm$ 2.7 -fold at $80 \mathrm{rpm}$. The reduced cell yield in the horizontal-blade reactor is likely linked to poor mixing that results in large, heterogeneous aggregates pictured in Fig. 3b. The aggregate distribution graphs for the horizontal-blade reactor (Fig. 3c) acquire either bi-model peaks or large, flat distributed averages, indicative of unhealthy aggregate morphology. By day 5 of culture, hiPSC aggregates in the horizontal-blade reactors reached over $400 \mu \mathrm{m}$ in diameter. Beyond this aggregate size threshold, necrosis is expected to occur with low levels of oxygen and nutrients diffusing into the center of the aggregate, resulting in heterogeneity in cell growth and differentiation potential [45]. hiPSCs cultured in the vertical-wheel bioreactors maintained consistent aggregate sizes with a single, narrow peak distribution at all tested agitation rates. Day 5 average aggregate sizes in the vertical-wheel reactor seeded with single cells remained below the threshold aggregate size, ranging between $169.4 \mu \mathrm{m} \pm 5.5 \mu \mathrm{m}$ and $275.45 \mu \mathrm{m} \pm 6.9 \mu \mathrm{m}$ in diameter at $80 \mathrm{rpm}$ and $40 \mathrm{rpm}$ respectively.

Next, pre-formed aggregate inoculation and single-cell inoculation methods were compared in the verticalwheel bioreactors. Under batch culture conditions, there were no differences in growth at corresponding agitation rates (Fig. 4a), with aggregate morphology remaining consistent between inoculation methods (Fig. 4b). At the tested agitation rates and inoculation methods, the cells experienced a lag phase on day 1 and entered the exponential growth phase on day 2 of culture. Batch and fed-batch single-cell inoculation in the vertical-wheel bioreactors was then compared (Fig. 4a'). At all tested agitation rates, fed-batch culture resulted in maximum fold expansions that were approximately twice that of batch culture conditions (Fig. 4c). Final cell concentrations at $40 \mathrm{rpm}$ were significantly higher than those at $60 \mathrm{rpm}$ and $80 \mathrm{rpm}$, with a maximum expansion of $32.3 \pm 3.2$-fold reached on day 6 of fed-batch culture. While there were significant differences in average aggregate size between the tested agitation rates, with average aggregate size decreasing in correspondence to an increase in agitation rate, average aggregate size within each agitation rate seeded as pre-formed or single cells remained the same (Fig. 4d).

\section{Bioreactor harvesting}

An optimized in-vessel harvesting protocol was developed by studying the effects of enzyme type and agitation exposure time on the dissociation efficiency and percentage of cells in aggregates. Accutase, TrypLE, and $0.05 \%$ Trypsin-EDTA were tested at exposure times of 5 , $10,15,20,25$, and $30 \mathrm{~min}$. A large reduction in the percent of aggregates occurred between 5 and $10 \mathrm{~min}$ for all tested enzymes (Fig. 5a). A further decrease in the 

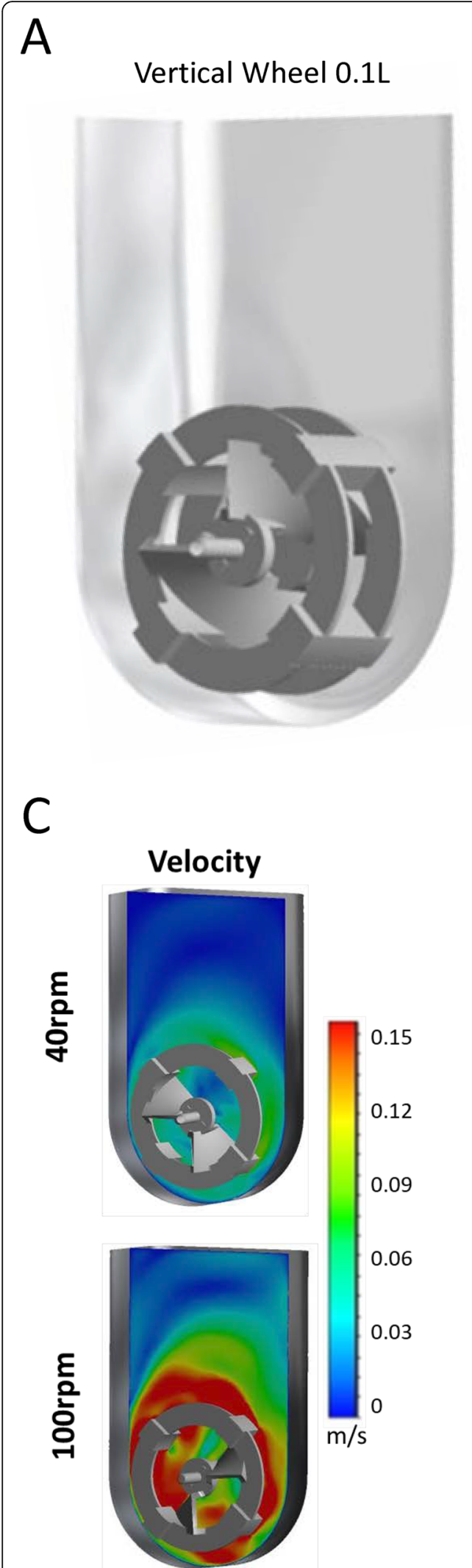

B
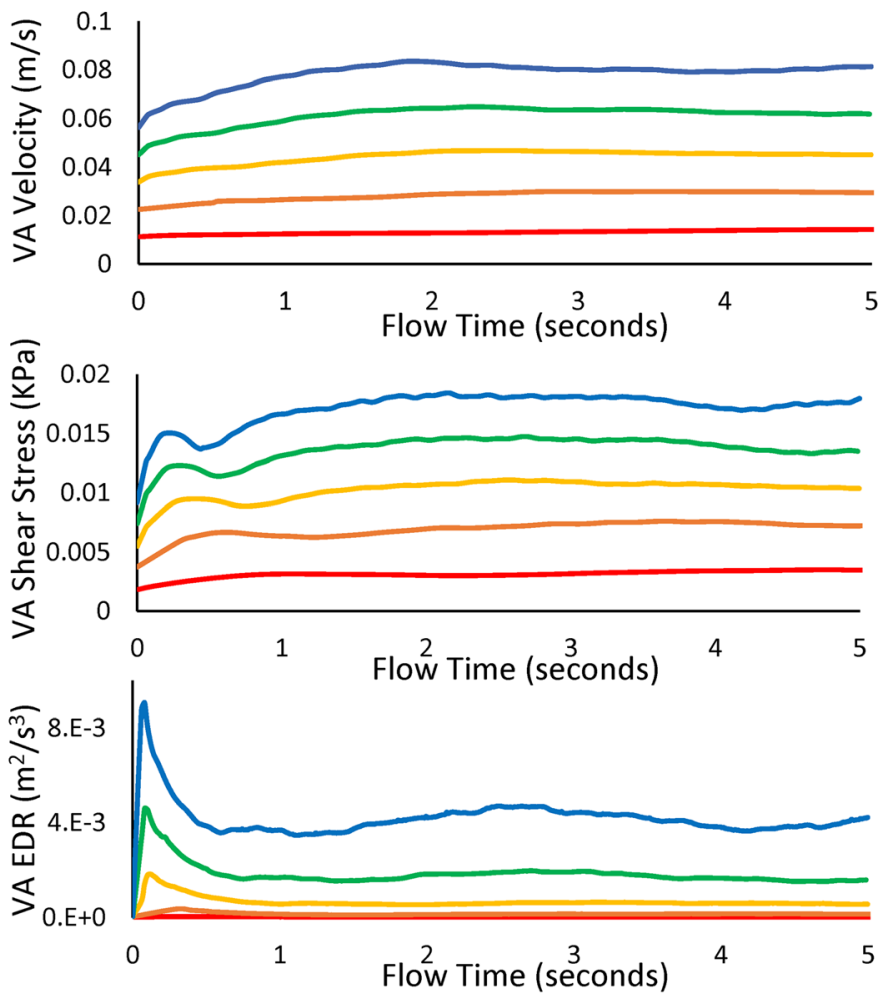

$-20 \mathrm{rpm}-40 \mathrm{rpm}-60 \mathrm{rpm}-80 \mathrm{rpm}-100 \mathrm{rpm}$

\section{Shear Stress}

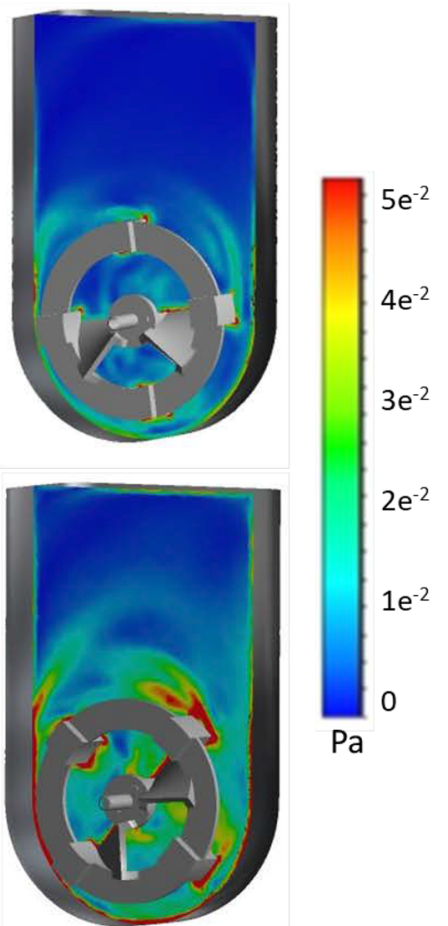

\section{Energy Dissipation}

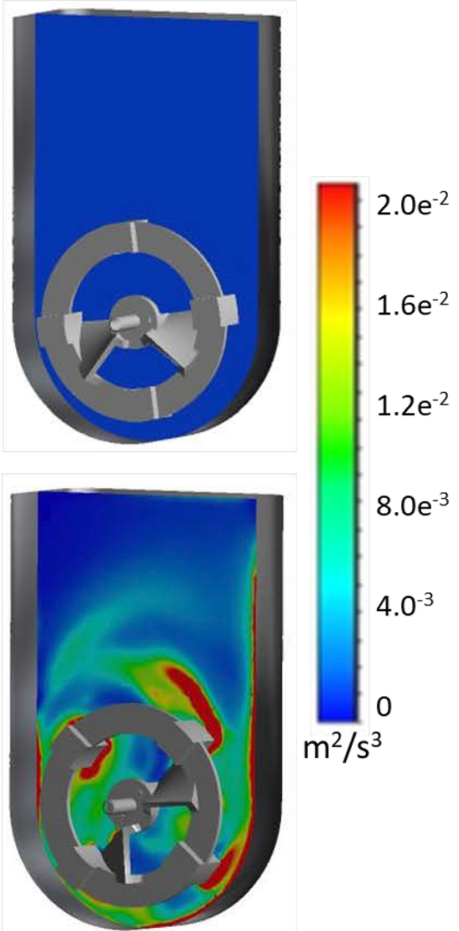

Fig. 1 (See legend on next page.) 
(See figure on previous page.)

Fig. 1 a Geometric outline of the 0.1 L PBS vertical-wheel bioreactor input into Ansys Fluent CFD modeling software. $\mathbf{b}$ Computational values for the volume average (VA) velocity, shear stress, and energy dissipation rate run for a flow time of $5 \mathrm{~s}$ at agitation rates between 20 and 100 rpm. $\mathbf{c}$ Vertical heatmap slices highlighting distributed areas of relatively high (red) and relatively low (blue) areas of local velocity, shear stress, and energy dissipation rate

number of aggregates continued until $20 \mathrm{~min}$ for all tested enzymes. After $20 \mathrm{~min}$, the percent of aggregates remains plateaued, indicating no further dissociation activity was occurring. When comparing enzyme types, the percent of aggregates remaining and the dissociation efficiency at the end of $20 \mathrm{~min}$ were considered. The dissociation efficiency at $20 \mathrm{~min}$ was calculated by comparing cell sample counts prior to the full reactor harvest with samples taken during the harvest and factoring in the percent of cells that remained in aggregates. Of the tested enzymes, $0.05 \%$ Trypsin resulted in the poorest performance, with a calculated dissociation efficiency of $82.9 \% \pm 10.0 \%$. The use of Accutase resulted in the highest dissociation efficiency of $95.2 \% \pm 4.0 \%$ and was therefore selected as the optimal enzyme for the in-vessel harvest protocol (Fig. 5b).

Figure $5 \mathrm{c}$ provides a visualization to support this observation where images were taken before dissociation began and at 5, 15, and $25 \mathrm{~min}$. After only $5 \mathrm{~min}$, dissociation was prevalent, with all aggregates visibly breaking apart into small clusters or single cells. By $15 \mathrm{~min}$, most of the smaller aggregates had dissociated, and by

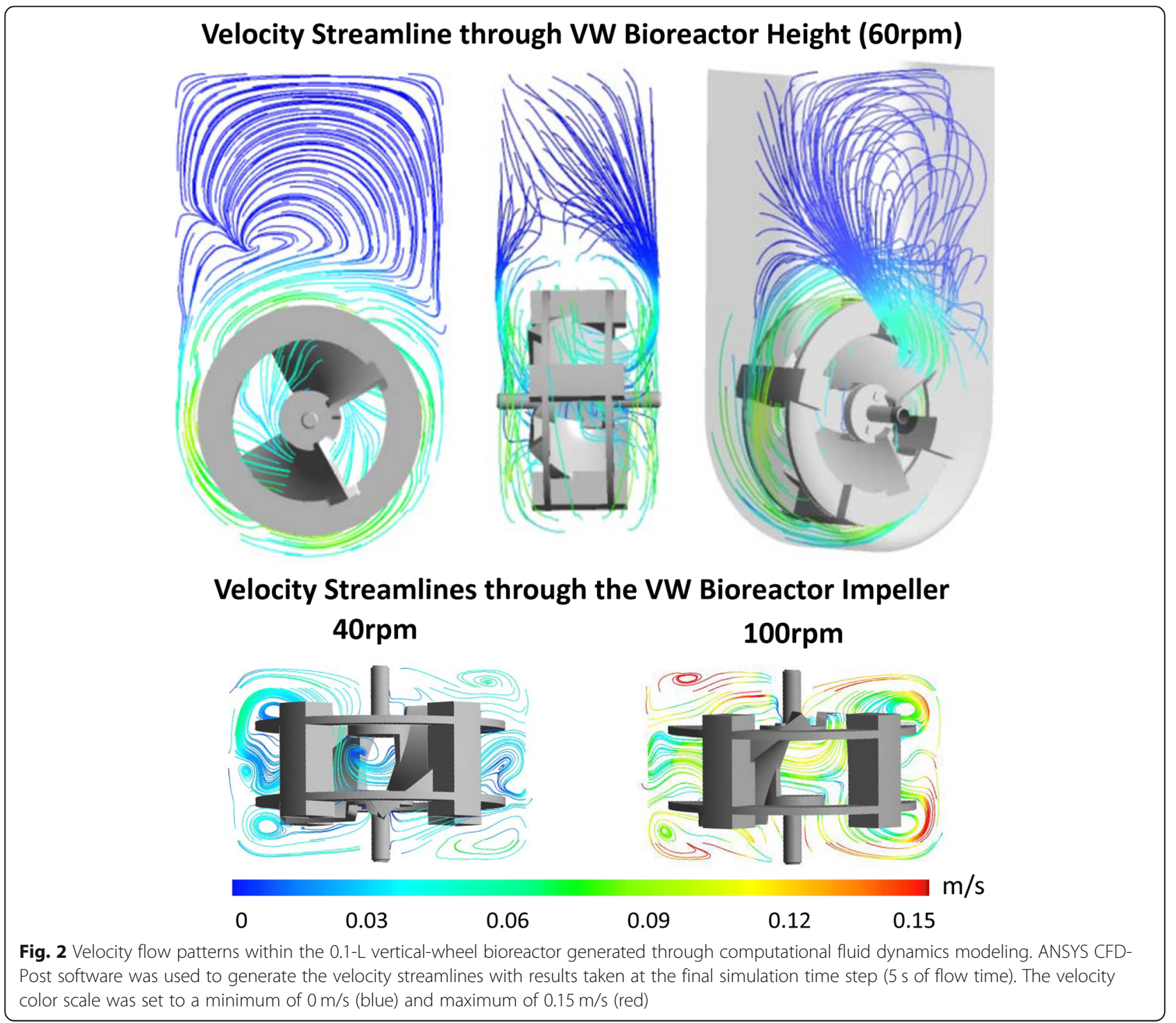




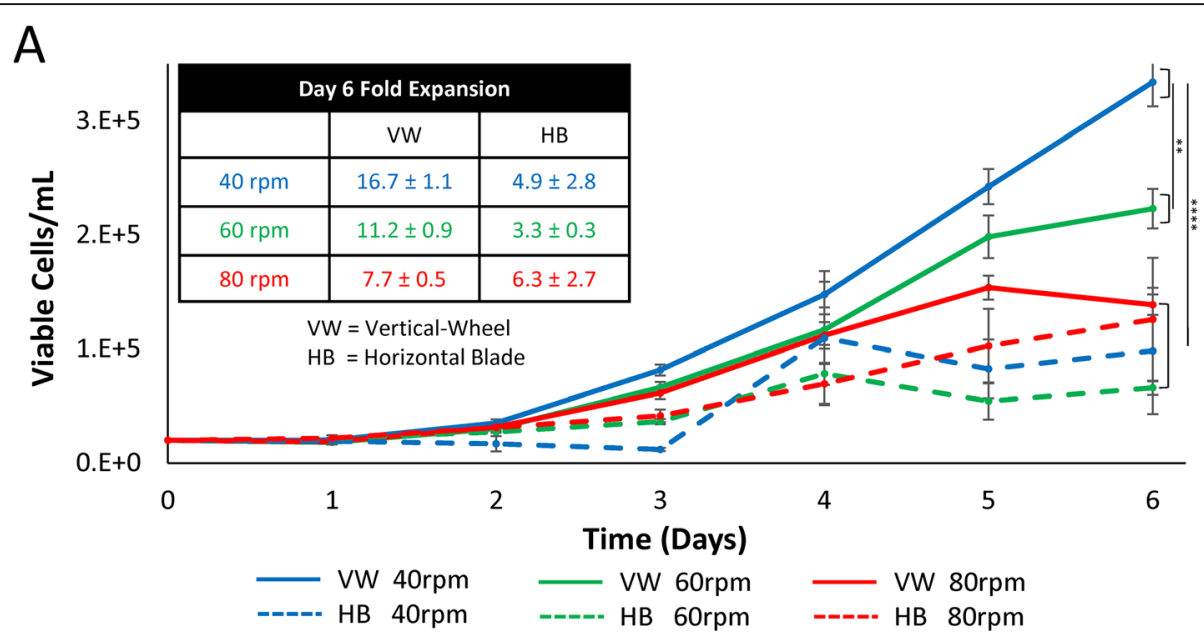

B
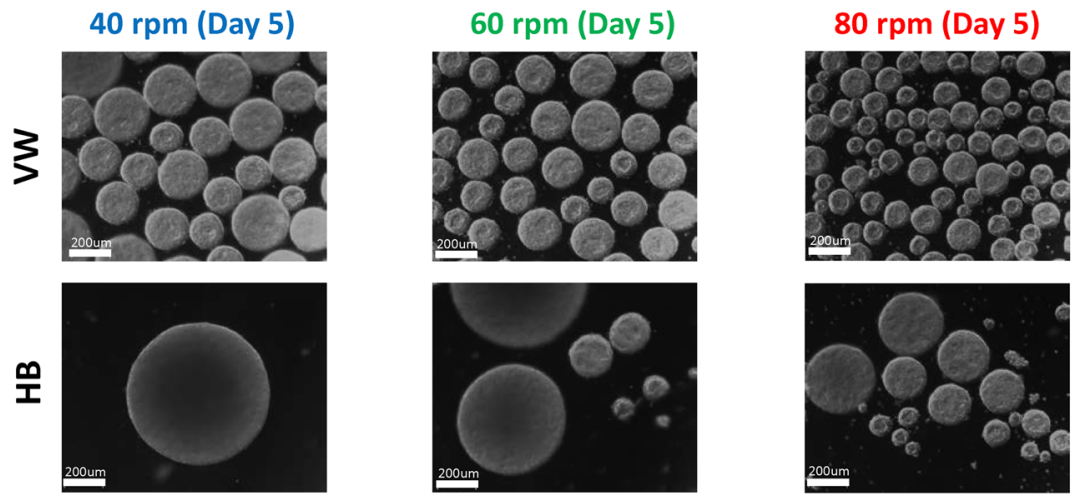

C
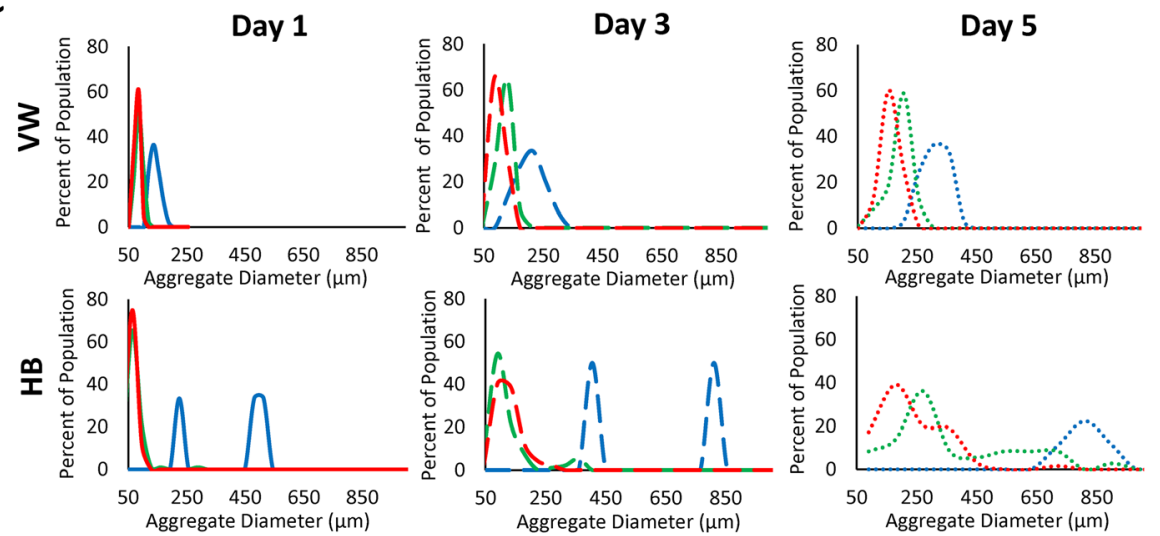

Fig. 3 a Growth kinetics, $\mathbf{b}$ representative brightfield microscopic images, and $\mathbf{c}$ aggregate size distributions of hiPSCs seeded as single cells and cultured in either vertical-wheel or horizontal-blade bioreactors at agitation rates of $40 \mathrm{rpm}, 60 \mathrm{rpm}$, and $80 \mathrm{rpm}$ with no medium exchange (batch) for 6 days (scale bar $=200 \mu \mathrm{m}$ ). Cell samples were collected from $n=4$ stirred suspension bioreactors at each condition. The $P$ values were set at 0.05 and all graphs are presented with a \pm standard error of the mean (SEM)

25 min, mostly single cells remained. As no further dissociation occurred after $20 \mathrm{~min}$, it was selected as the optimal agitated exposure time.

Following the bioreactor harvest using Accutase for 20 min, single-cell samples were assessed using immunocytochemistry. The cells maintained positive expression for human pluripotency markers SSEA-4, TRA-1-60, and Nanog (Fig. 5d). In addition, proliferative capabilities were assessed by recovering the dissociated single cells in static T-75 flasks coated with Matrigel. Typical hiPSC static morphology and growth was observed over 4 days of recovery culture (Fig. 5e). 


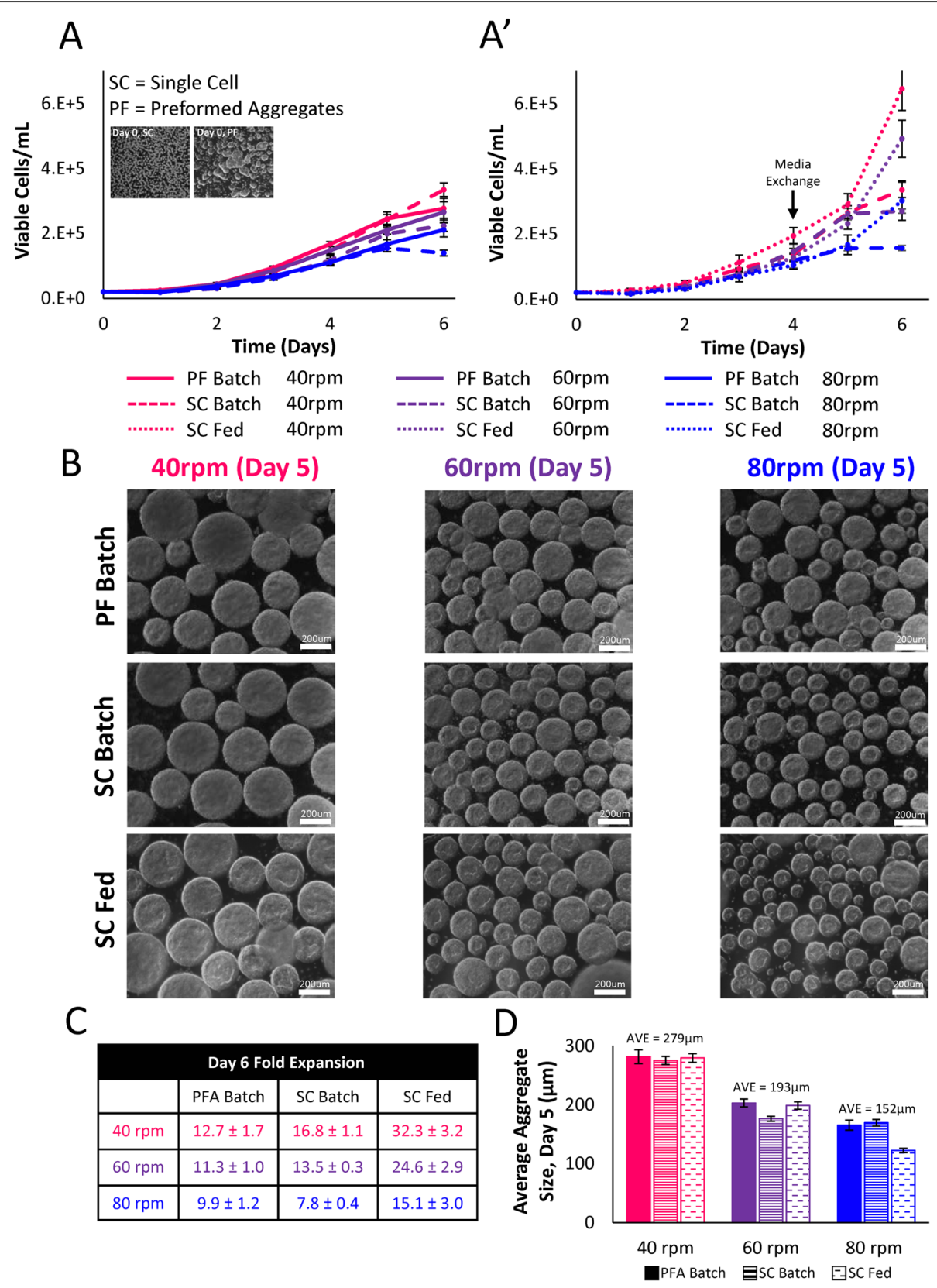

Fig. 4 a Growth kinetics for hiPSCs seeded as either single cells or pre-formed aggregates cultured in vertical-wheel bioreactors at agitation rates of $40 \mathrm{rpm}, 60 \mathrm{rpm}$, and $80 \mathrm{rpm}$ with no medium exchange (batch) for a period of 6 days. a' Growth kinetics for hiPSCs seeded as single cells in vertical-wheel bioreactors at agitation rates of $40 \mathrm{rpm}, 60 \mathrm{rpm}$, and $80 \mathrm{rpm}$ with either no medium exchange (batch) for 6 days or a $50 \%$ medium exchange on day 4 (fed) of the 6-day culture period. b Representative brightfield microscopic images, $\mathbf{c}$ day-6 fold expansions, and $\mathbf{d}$ average aggregate sizes of hiPSCs cultured in vertical-wheel bioreactors under pre-formed (PF) batch, single-cell (SC) batch, and single-cell (SC) fed conditions at agitation rates of $40 \mathrm{rpm}, 60 \mathrm{rpm}$, and $80 \mathrm{rpm}$ (scale bar $=200 \mu \mathrm{m}$ ). Cell samples were collected from $n=4$ stirred suspension bioreactors at each condition. The $P$ values were set at 0.05 and all graphs are presented with a \pm standard error of the mean (SEM)

\section{Serial passaging and quality testing}

Finally, optimized protocols for single-cell inoculation and bioreactor harvesting were combined in a serial passage experiment with cell quality testing performed on the final day of culture. We implemented successes from previous experiments, inoculating single cells into the
100-mL vertical-wheel reactor at $40 \mathrm{rpm}$ to be cultured under fed-batch conditions. On day 6 of culture, a full bioreactor harvest using Accutase for $20 \mathrm{~min}$ was performed and single cells were re-seeded into additional $100 \mathrm{~mL}$ and scaled-up 500-mL vertical-wheel reactors for another passage. Cell growth (Fig. 6a) and aggregate 

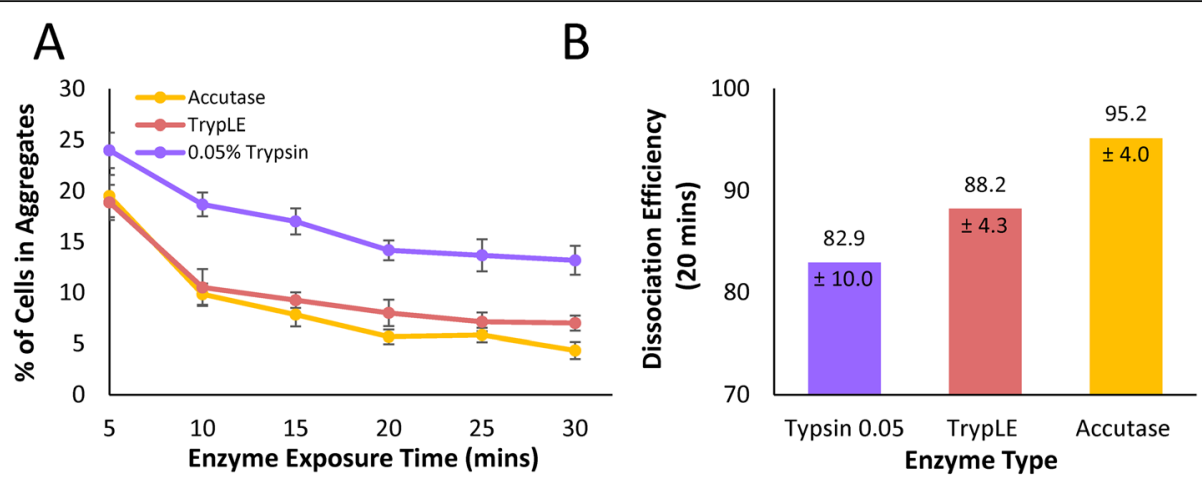

\section{C}
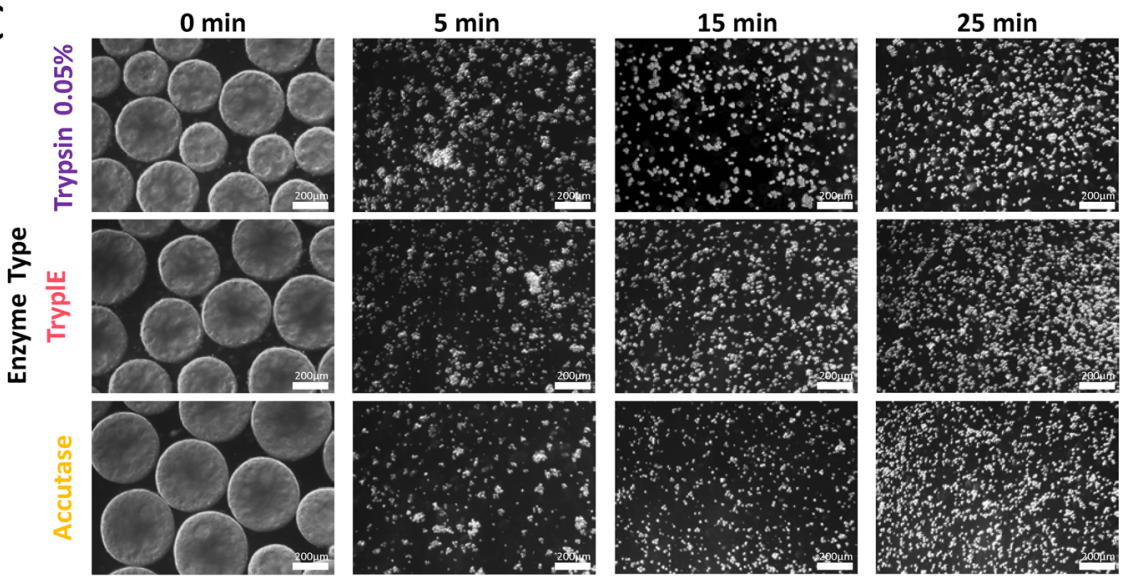

D

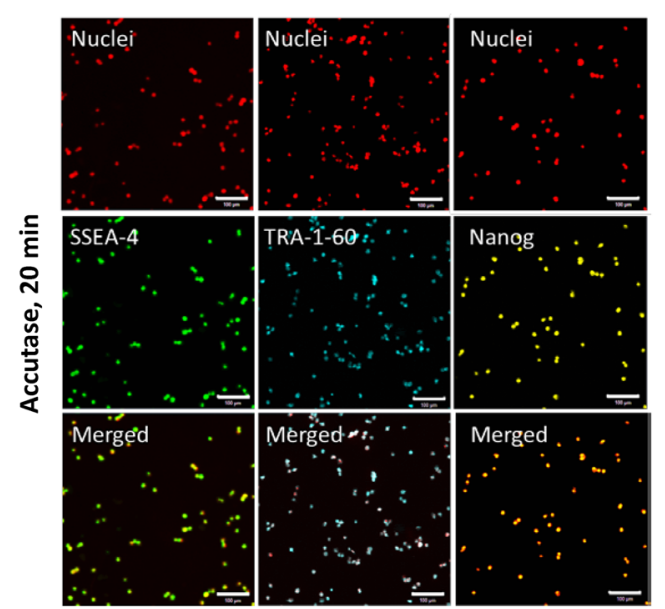

$\mathrm{E}$
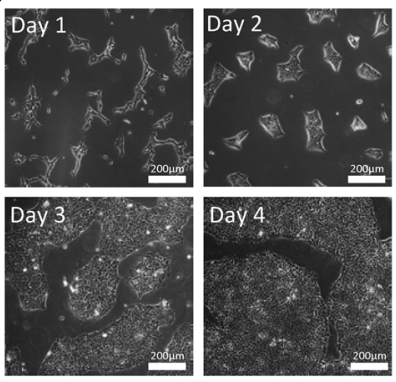

Static Recovery

(Accutase, $20 \mathrm{~min}$ )

Fig. 5 a Percent of cells in aggregates, $\mathbf{b}$ dissociation efficiency, and $\mathbf{c}$ representative brightfield microscopic images of hiPSC aggregates exposed to either Accutase, TrypLE, or 0.05\% Trypsin for periods of 5-30 min during full bioreactor harvesting (scale bar $=200 \mu \mathrm{m}$ ). $\mathbf{d}$ Representative confocal microscope images of hiPSC single-cell samples taken from the full bioreactor harvest (Accutase for $20 \mathrm{~min}$ ) and stained for pluripotency markers SSEA-4, TRA-1-60, and Nanog (scale bar $=100 \mu \mathrm{m}$ ). e Representative brightfield microscope images of hiPSCs taken from the full bioreactor harvest (Accutase for $20 \mathrm{~min}$ ) and seeded onto Matrigel-coated dishes for static recovery (scale bar $=200 \mu \mathrm{m}$ ). Cell samples were collected from $n=4$ stirred suspension bioreactors at each condition. The $P$ values were set at 0.05 and all graphs are presented with a \pm standard error of the mean (SEM)

morphology (Fig. 6b) in the second passage in the 100-mL and $500-\mathrm{mL}$ vertical-wheel bioreactors were comparable to that of the first. Importantly, there was no extended lag phase present in the second bioreactor passage, indicating that the aggregates were still within a healthy growth range and that extended enzyme exposure during the harvest did not impact serial expansion. When cells reach oxygen or nutrient limitations before passaging, they exit the exponential growth phase and enter a plateau or cell death phase. This delay in subculturing can result in a significant decrease in cell fold expansion and stem cell differentiation 


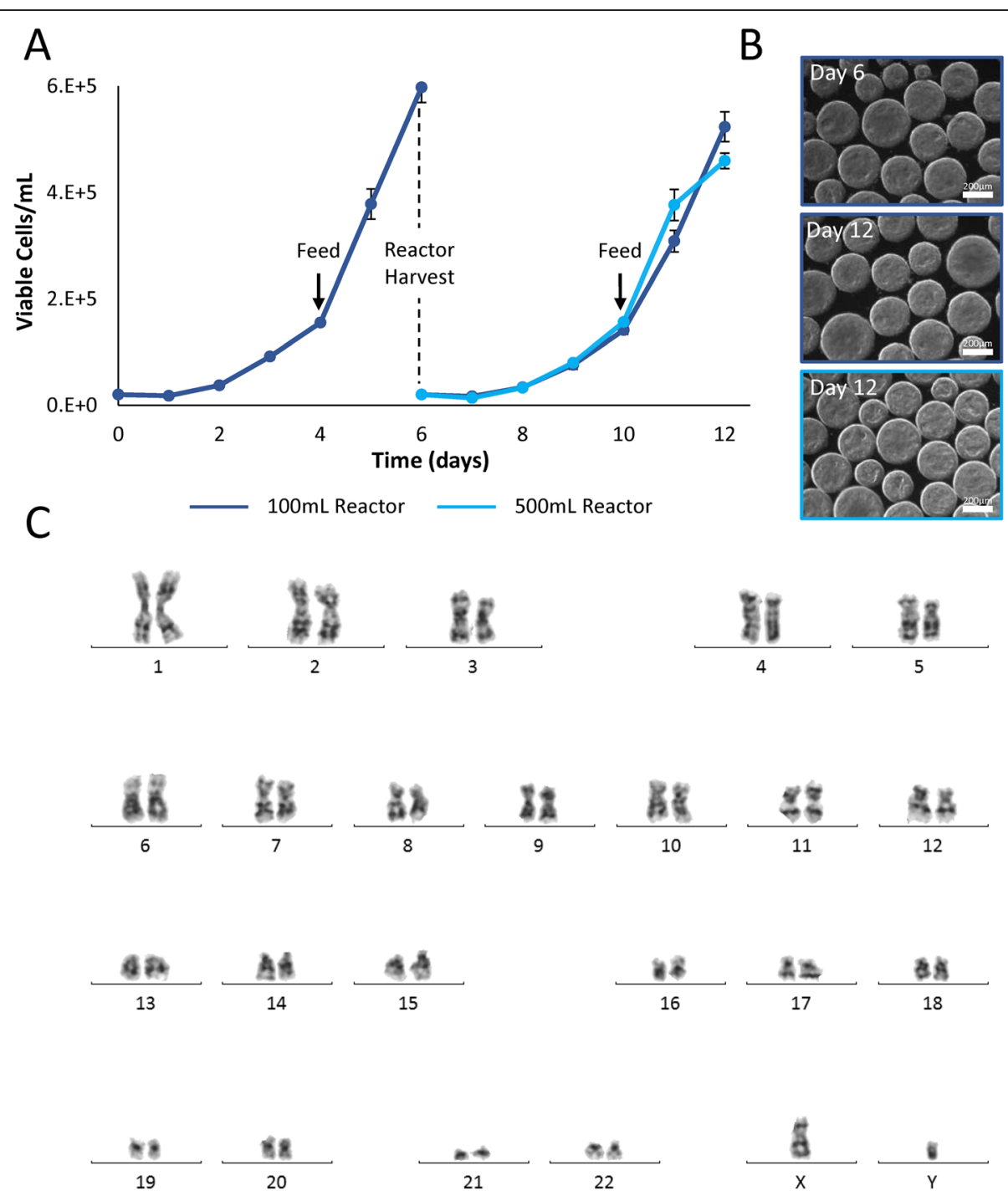

Fig. 6 a Growth kinetics and $\mathbf{b}$ representative brightfield microscope images of hiPSCs seeded as single cells cultured in 0.1- $L$ vertical-wheel bioreactors and serially passaged into $0.1-\mathrm{L}$ and $0.5-\mathrm{L}$ vertical-wheel bioreactors (scale bar $=200 \mu \mathrm{m}$ ). c Karyogram analysis of hiPSCs taken from the final day of the vertical-wheel bioreactor serial passage (day 12). Cell samples were collected from $n=4$ stirred suspension bioreactors at each condition. The $P$ values were set at 0.05 and all graphs are presented with a \pm standard error of the mean (SEM)

potential in the next passage, which was not observed in this case [46-48].

Additional samples were collected at the end of the 12-day culture period to assess genomic stability and to determine phenotypic and functional pluripotency quality. Following the 12-day optimized expansion process in the vertical-wheel bioreactors, the hiPSCs presented with a normal chromosome complement (Fig. 6c). hiPSC aggregates maintained expression for human pluripotency markers SSEA-4, TRA-1-60, and Nanog, with confocal slices displaying no difference in spatial expression between the outer edge and the center of the aggregates (Fig. 7a). Directed tri-lineage differentiation into neural cells, hepatocytes, and cardiomyocytes demonstrated that the hiPSCs retained full pluripotency after bioreactor culture, functionally generating cells from the three germ layers (Fig. 7b). Negative control confocal images are included in Supplementary Fig. 1. Pluripotency-associated genes showed either comparable (i.e., Oct-4, Nanog, and Rex1) or higher (i.e., Sox2 and Klf4) expression in hiPSCs following serial passaging in bioreactors compared to their static cultured counterpart (Fig. 8). This corroborates the maintenance of pluripotency state following several passages of hiPSCs in vertical-wheel bioreactors.

\section{Discussion}

The ability of hiPSCs to mimic traditional hESC selfrenewal capacity and functional pluripotency potential 
A

$100 \mathrm{~mL}$ Reactor, Day 12 Aggregate Staining
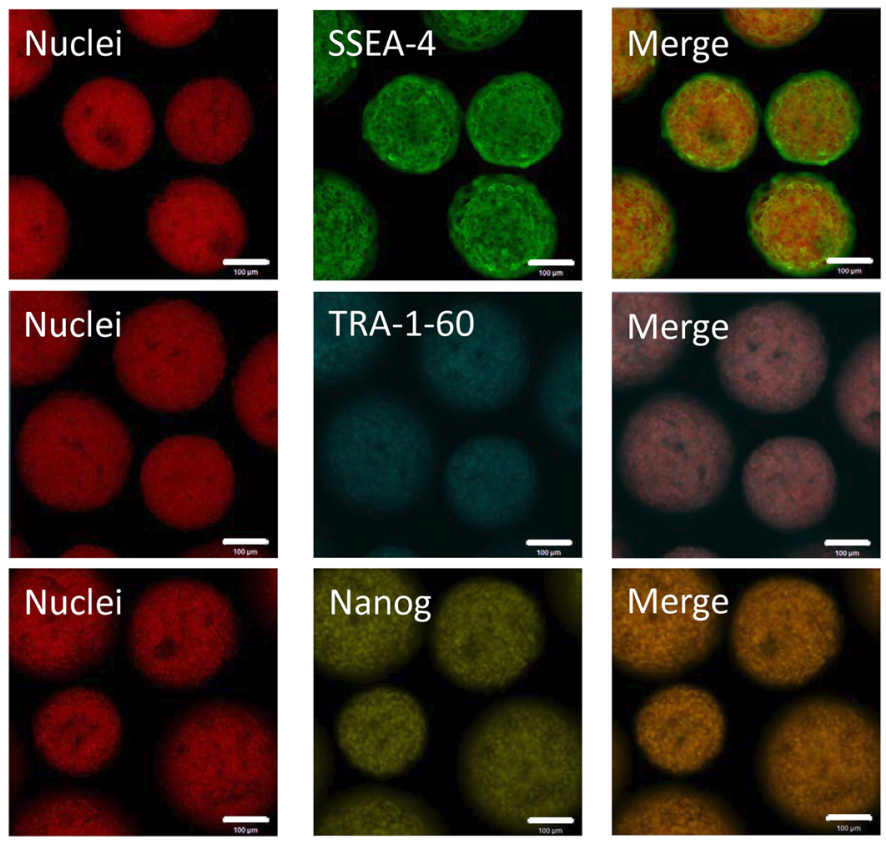

B
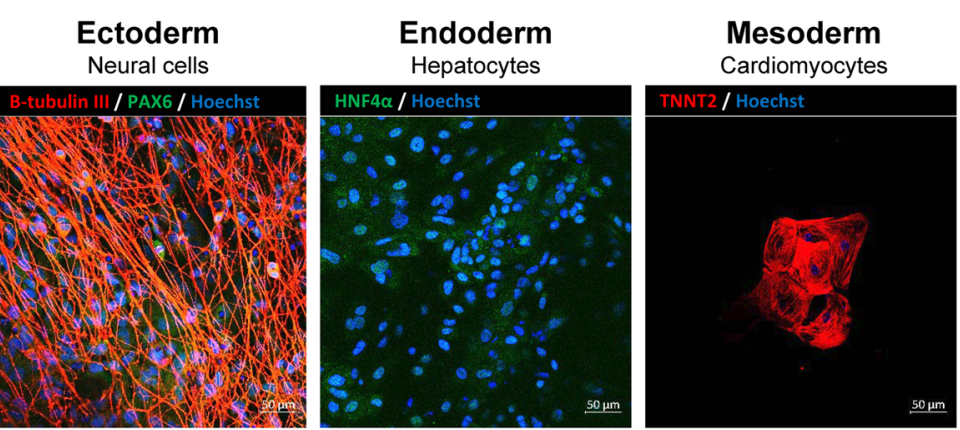

Fig. 7 a Representative confocal microscope images of hiPSC aggregates taken from the final day of the vertical-wheel bioreactor serial passage (day 12) and stained for pluripotency markers SSEA-4, TRA-1-60, and Nanog (scale bar $=100 \mu \mathrm{m}$ ) and $\mathbf{b}$ differentiated into neuronal cells (immuno-stained for $\beta$-tubulin and PAX6), hepatocytes (immuno-stained for HNF4a), and cardiomyocytes (immuno-stained for TNNT2) (scale bar $=50 \mu \mathrm{m})$

in vitro and in vivo make them an ideal cell type for generating large quantities of differentiated cells needed for regenerative medicine applications [49]. Epigenetic reprogramming of hiPSCs from somatic cells provides the unique opportunity for personalized regenerative medicine with reduced risks of rejection as well as largescale disease modeling studies that would otherwise be restricted due to limited availability of primary cells and biopsy material. The transfer of laboratory processes into a manufacturing facility, however, is one of the most critical steps required for the production of cell-based therapies and products and is currently bottlenecked by a lack of scalable bioprocess protocols for production of clinical quantities of high-quality hiPSCs [50].

While stirred-tank bioreactors offer several advantages for stem cell manufacturing, there are major limitations related to the complex hydrodynamics and high shear stress at the impeller tip. Traditional stirred-tank bioreactors employ horizontal-blade or turbine impellers that require careful optimization at each scale. The shear stress at the impeller tip increases with reactor scale, limiting the successful scale-up of shear-sensitive stem cells [51]. The vertical-wheel bioreactor that was hydrodynamically characterized and utilized in this study could prove to be invaluable to overcoming these hurdles for scale-up of hiPSCs, which are among the most difficult cell types to cultivate. Unlike mouse cells, human pluripotent stem cells differentiate extensively when cultured as aggregates in stirred suspension bioreactors [52]. Even compared to traditional hESCs, hiPSCs display slower growth kinetics and impaired directed differentiation, making an optimized culture environment especially important for their successful cultivation [53]. As highlighted by the CFD models generated in this 
A
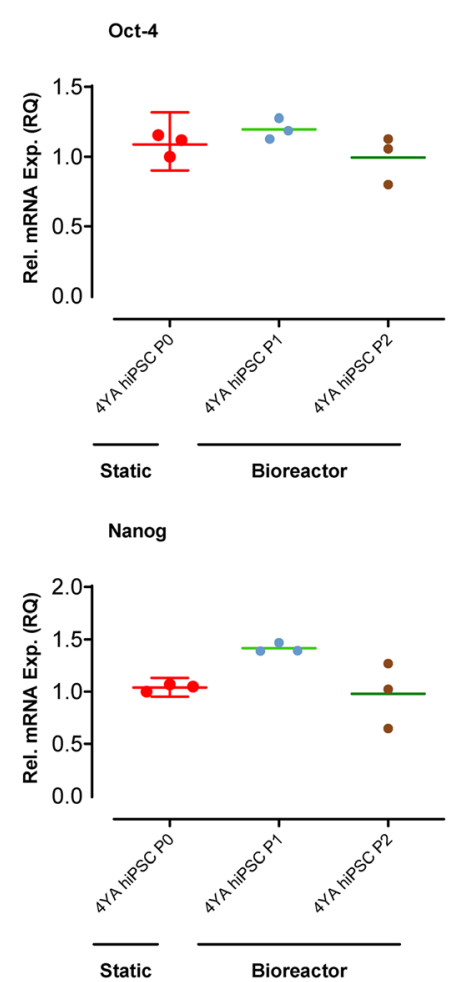

E

$\operatorname{Rex1}$

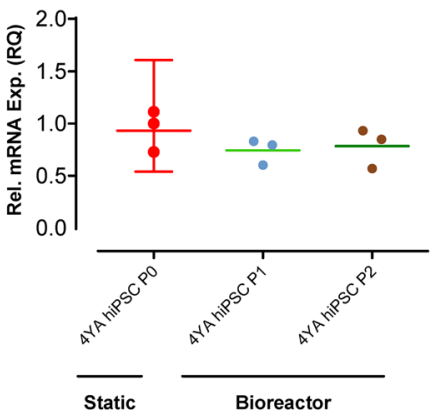

B

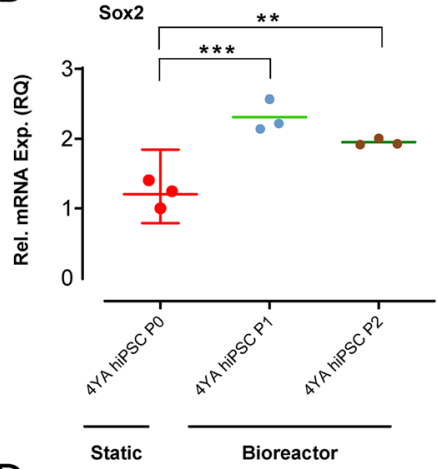

D

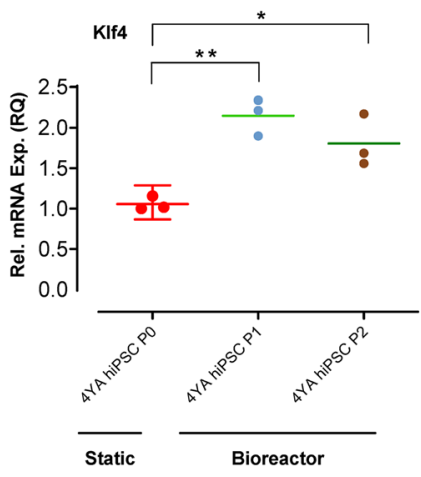

Fig. 8 Dotplot geometric mean linear depictions of pluripotency-associated genes a Oct-4, b Sox2, c Nanog, d Klf4, and e Rex 1 expression levels in hiPSCs analyzed by RT-qPCR. hiPSCs cultured in static conditions (PO) were used as a control reference sample. hiPSCs were analyzed following expansion in vertical-wheel bioreactors $(P 1=$ day 6 and $P 2=$ day 12). Expression was quantified relative to the housekeeping gene GAPDH and was normalized to static culture hiPSC level $(=1)$. RQ relative quantification

study, the vertical-wheel reactor is unique in its mixing ability, directing fluid streamlines in a lemniscate pattern throughout the entire volume of the reactor. This results in a more uniform distribution of hydrodynamic forces and a lower shear stress environment, ideal for hiPSC growth as aggregates. The hydrodynamic distribution of energy dissipation rate, which scales exponentially with an increase in agitation, is a controlling variable dictating average aggregate size and size distributions [54]. Among the lower agitation rates modeled $(40 \mathrm{rpm})$, the energy dissipation rate remained homogeneous throughout the vertical-wheel volume, leading the authors to believe that hiPSC aggregates could be successfully cultured as single cells in this bioreactor environment.

When single-cell inoculation of hiPSCs was tested in traditional horizontal-blade bioreactors, the authors were unsuccessful in generating consistent aggregate sizes. At all tested agitation rates $(40 \mathrm{rpm}, 60 \mathrm{rpm}$, and $80 \mathrm{rpm}$ ), aggregate distributions were bi-model or spread out in nature corresponding to low cell yields. This could be a result of the predominantly radial mixing present within the horizontal-blade bioreactor that limits aggregates from moving throughout the entire volume. Our previous work modeling 100-mL horizontal-blade 
bioreactors highlighted differences in hydrodynamics between the vertical planes in the reactor [33, 54]. Above and below the impeller blade were areas with relatively low hydrodynamic values and fluid dead zones. Conversely, the middle section of the working volume height experienced relatively high hydrodynamic forces. If aggregates in the horizontal-blade reactor flow in a mostly radial fashion along with the fluid, they will become trapped in either a high shear zone (small aggregates) or a low shear zone (large aggregates). Single-cell hiPSC inoculation was successful in the vertical-wheel bioreactors, producing a narrow distribution of aggregate sizes at each agitation rate with high cell fold expansions, particularly at $40 \mathrm{rpm}$. With a fed-batch feeding strategy employed, over 30-fold expansion in 6 days was achieved, which is significantly higher than other published studies which inoculate hiPSCs in bioreactors using cell clumps or single cells at high cell densities $\left(2 \times 10^{5}-1 \times 10^{6}\right.$ cells $\left./ \mathrm{mL}\right)$. Early publications achieve a maximum of 6-fold expansion in 4 to 7 days [15], while recent publications achieve a maximum of 10-fold expansion in 12 days [55] and 10- to 16-fold expansion in 7 days [56].

Literature has indeed provided evidence that hiPSCs harvested as single cells are more likely to acquire genetic abnormalities [57]. Conventional methods used to subculture hiPSCs include manual scraping and microdissection as well as enzymatic and non-enzymatic procedures to detach cell clumps from their matrix. Manual methods to select colonies are labor intensive and highly dependent on the proficiency of skilled technical personal, making them infeasible for a manufacturing setting [58]. Passaging of cell clumps lacks standardization in counting and measuring clump sizes, making it impractical for large-scale, reproducible results [50]. Clump sizes are difficult to control resulting in increased heterogeneity in the seeding population $[11,24]$. The precise number and spatial coordination of various cell-cell interactions involved in aggregate growth and embryoid body formation influences cell quality and the course of cell differentiation, making a controlled aggregate population an essential consideration [59, 60]. While others have shown that under certain culture conditions single-cell inoculated hiPSC maintenance of pluripotency and karyotype stability is possible [61, 62], to the best of our knowledge, current publications have not investigated bioreactor harvesting of hiPSC aggregates dissociated into single cells for serial passaging. Bioreactor harvesting is an essential step in manufacturing scale-up of stem cell culture but is rarely investigated. The authors were successful in designing a full reactor harvest protocol for the dissociation of hiPSC aggregates into single cells. This involved finding an appropriate enzyme, exposure time, reduced working volume, and agitation rate within the reactor to dissociate aggregates into single cells without sacrificing the cells ability to recover in growth and maintain pluripotent quality characteristics. Recently, bioprocess publications have investigated bioreactor harvesting of mesenchymal stromal cells grown on microcarriers [63-66]. These studies optimized protocols by testing many of the same variables, but recovery yields generally hovered around $80 \%$. This reduced recovery, compared to the $95 \%$ achieved in this study, is likely attributed to the additional challenges associated with separating the cells from the microcarriers through a multifiltration and washing process.

Importantly, the cells harvested and re-inoculated as single cells in both $0.1-\mathrm{L}$ and scaled-up $0.5-\mathrm{L}$ verticalwheel bioreactors not only maintained consistent growth kinetics, they maintained a normal karyotype and pluripotent function after 12 days of bioreactor culture. While there are a few studies with mouse ESCs cultured on microcarriers [67-69] or as aggregates [70], there lacks a robust method for serial culturing of human ESCs in stirred suspension culture. A recent publication [71] demonstrated that hESCs cultured on microcarriers often lose their stemness through successive passages. In this study, 3-fold expansion was initially achieved over 5 days; however, with each successive passage, cell expansion was reduced until cells could not be passaged. In our recent publication [41], we showed that hiPSCs could be cultured through successive serial passages in the vertical-wheel bioreactor with expansions ranging between 30 and 35 -fold each passage. While we were able to show that growth and pluripotency could be maintained in the bioreactors, the protocol required preformed aggregate inoculation and a cell sample passaging protocol, limiting our ability to scale-up the process. Additionally, it was noted that inconsistent lag phases resulted between passages, such that culture periods would range between 6 and 8 days. These inconsistencies in passage length are not acceptable in a manufacturing setting. By utilizing single-cell inoculation and the full reactor harvest protocol optimized in this study, the increased lag phase was not observed in the serial passage. The hiPSCs generated in the vertical-wheel reactor maintained high-quality standards in the generation of morphologically healthy and homogenous aggregates. The cells maintained a normal karyotype, an expression of characteristic pluripotency markers, and the ability to differentiate into cell types of all three germ layers. It should be noted that the tri-lineage differentiation performed in this study was of a qualitative nature. There are numerous bioprocess challenges associated with obtaining high differentiation efficiencies which the authors hope to address in future studies. The methods optimized in this study for generation of large quantities of high-quality hiPSCs in the vertical-wheel bioreactor overcome some of the major bottlenecks in moving production to the clinical and manufacturing setting. 


\section{Conclusions}

hiPSCs carry enormous promise for breakthroughs in understanding human development, drug screening, disease modeling, and cell and gene therapies; however, their therapeutic potential has been bottlenecked in a laboratory setting due to bioprocess challenges in scale-up of large quantities of high-quality cells. This study focused on characterizing and optimizing the use of vertical-wheel bioreactors as a tool to overcome hiPSC production challenges. The unique bioreactor geometry provided a low shear stress environment with a more homogeneous distribution of hydrodynamic forces. While a single-cell hiPSC inoculation method proved unsuccessful in traditional horizontal-blade bioreactors, the vertical-wheel environment supported healthy morphological aggregate growth, high cell fold expansions, and maintenance of pluripotency cell quality. This study also includes the first published protocol for in-vessel hiPSC aggregate harvesting, permitting the entire bioreactor volume to be dissociated into single cells for serial passaging and scale-up. These protocols provide a feasible solution for the culture of high-quality hiPSCs at a clinical and manufacturing scale by overcoming some of the major documented bioprocess bottlenecks.

\section{Supplementary Information}

The online version contains supplementary material available at https://doi. org/10.1186/s13287-020-02109-4.

Additional file 1: Supplementary Table 1. Primer sequences used for RT-qPCR analysis.

Additional file 2: Supplementary Fig. 1. Representative confocal images are shown for negative control staining. Scale bars $=50 \mu \mathrm{m}$.

\section{Abbreviations}

CAD: Computer-aided design; CFD: Computational fluid dynamics; CFL: Courant-Friedrich-Lewy; hiPSC: Human induced pluripotent stem cell; PBS: Phosphate buffer solution; PIV: Particle image velocimetry; rpm: Revolution per minute; RT-qPCR: Reverse transcription quantitative polymerase chain reaction; RQ: Relative quantification; SEM: Standard error of the mean; SIMPLE: Semi-implicit method for pressure-linked equations

\section{Acknowledgements}

We thank the Stem Cell Network for their generous and continued support in trainee development.

\section{Authors' contributions}

Breanna S. Borys: concept and design, collection and assembly of data, data analysis and interpretation, and manuscript writing. Tiffany Dang: concept and design, collection and assembly of data, data analysis and interpretation, and manuscript writing. Tania So: concept and design, collection and assembly of data, and data analysis and interpretation. Leili Rohani: collection and assembly of data and data analysis and interpretation. Tamas Revay: collection and assembly of data and data analysis and interpretation. Tylor Walsh: collection and assembly of data. Madalynn Thompson: collection and assembly of data. Bob Argiropoulos: manuscript review, editing, and supervision. Derrick E. Rancourt: manuscript review, editing, and supervision Sunghoon Jung: concept and design, manuscript review, and editing. Yas Hashimura: concept and design, manuscript review, and editing. Brian Lee: concept and design, manuscript review, and editing. Michael S. Kallos: concept and design, manuscript review, editing, and supervision. The authors read and approved the final manuscript.

\section{Funding}

This project was funded by the NSERC Discovery Grant Program and Collaborative Health Research Projects (NSERC Partnered). B. Borys was funded by the Vanier Canada Graduate Scholarship Program. T. Revay acknowledges the support of the Alberta Children's Hospital Research Institute Clinical Research Fellowship.

\section{Availability of data and materials}

Not applicable

Ethics approval and consent to participate

Not applicable

\section{Consent for publication}

Not applicable

\section{Competing interests}

Yas Hashimura and Sunghoon Jung are employees of PBS Biotech, Inc. Brian Lee is the CEO and co-founder of PBS Biotech, Inc. These collaborating authors participated in the development of the bioreactors used in the manuscript as well as the experimental concept design and data review. PBS Biotech, Inc. provided financial support for the researchers to complete the study. This does not alter the authors' adherence to all the policies of the journal. All other authors declare no competing interests.

\section{Author details}

${ }^{1}$ Pharmaceutical Production Research Facility, Schulich School of Engineering, University of Calgary, 2500 University Dr. NW, Calgary, AB T2N 1N4, Canada. ${ }^{2}$ Biomedical Engineering Graduate Program, University of Calgary, 2500 University Dr. NW, Calgary, AB T2N 1N4, Canada. ${ }^{3}$ Department of Chemical and Petroleum Engineering, Schulich School of Engineering, University of Calgary, 2500 University Dr. NW, Calgary, AB T2N 1N4, Canada. ${ }^{4}$ Department of Biochemistry and Molecular Biology, Cumming School of Medicine, University of Calgary, 3330 Hospital Dr. NW, Calgary, AB T2N 4N1, Canada. ${ }^{5}$ Department of Medical Genetics, Alberta Health Services, Alberta Children's Hospital, 28 Oki Drive, Calgary, AB T3B 6A8, Canada. ${ }^{6}$ PBS Biotech Inc, 1183 Calle Suerte, Camarillo, CA 93012, USA.

Received: 25 August 2020 Accepted: 21 December 2020 Published online: 13 January 2021

\section{References}

1. Placzek MR, Chung IM, Macedo HM, Ismail S, Blanco TM, Lim M, et al. Stem cell bioprocessing: fundamentals and principles. J R Soc Interface Royal Society. 2009;6:209-32.

2. Sart S, Schneider YJ, Li Y, Agathos SN. Stem cell bioprocess engineering towards CGMP production and clinical applications. Cytotechnology. 2014: 709-22.

3. Rodrigues CA, Nogueira DE, Cabral JM. Next-generation stem cell expansion technologies. Cell Gene Ther Insights. 2018 [cited 2020 Jan 13];4:791-804. Available from: https://insights.bio/cell-and-gene-therapy-insights/?bio_ journals=next-generation-stem-cell-expansion-technologies.

4. Takahashi K, Yamanaka S. Induced pluripotent stem cells in medicine and biology. Development The Company of Biologists; 2013;140:2457-2461.

5. Shi Y, Inoue H, Wu JC, Yamanaka S. Induced pluripotent stem cell technology: a decade of progress. Nat Rev Drug Discov:; 2017 [cited 2019 Sep 10];16:115-30. Available from: http://www.nature.com/articles/nrd.2 016.245 .

6. Kropp C, Massai D, Zweigerdt R. Progress and challenges in large-scale expansion of human pluripotent stem cells. Process Biochem. Elsevier; 2017 [cited 2018 Jun 8];59:244-54. Available from: https://www.sciencedirect. com/science/article/pii/\$1359511316303907.

7. Scudellari M. How iPS cells changed the world. Nature. 2016 [cited 2019 Sep 10];534:310-2. Available from: http://www.nature.com/articles/534310a.

8. Avior Y, Sagi I, Benvenisty N. Pluripotent stem cells in disease modelling and drug discovery. Nat. Rev. Mol. Cell Biol; 2016. p. 170-182.

9. Abbasalizadeh S, Baharvand $\mathrm{H}$. Technological progress and challenges towards CGMP manufacturing of human pluripotent stem cells based 
therapeutic products for allogeneic and autologous cell therapies. Biotechnol. Adv. 2013. p. 1600-23.

10. Jenkins MJ, Farid SS. Human pluripotent stem cell-derived products: advances towards robust, scalable and cost-effective manufacturing strategies. Biotechnol J. 2015 [cited 2019 Sep 10];10:83-95. Available from: http://doi.wiley.com/10.1002/biot.201400348.

11. Chen KG, Mallon BS, McKay RDG, Robey PG. Human pluripotent stem cell culture: considerations for maintenance, expansion, and therapeutics. Cell Stem Cell. 2014:13-26.

12. Serra M, Brito C, Correia C, Alves PM. Process engineering of human pluripotent stem cells for clinical application. Trends Biotechnol; 2012 [cited 2018 Jun 8];30:350-9. Available from: https://www.sciencedirect.com/ science/article/pii/S0167779912000352.

13. Rodrigues CAV, Fernandes TG, Diogo MM, da Silva CL, Cabral JMS. Stem cell cultivation in bioreactors. Biotechnol Adv; 2011 [cited 2019 Sep 10];29:81529. Available from: https://www.sciencedirect.com/science/article/pii/S0734 975011000851.

14. Cherry RS, Papoutsakis ET. Hydrodynamic effects on cells in agitated tissue culture reactors. Bioprocess Eng; 1986 [cited 2017 Jul 19];1:29-41. Available from: http://link.springer.com/10.1007/BF00369462.

15. Zweigerdt $R$, Olmer $R$, Singh $H$, Haverich $A$, Martin U. Scalable expansion of human pluripotent stem cells in suspension culture. Nat Protoc; 2011 [cited 2019 Sep 10];6:689-700. Available from: http://www.nature.com/articles/ nprot.2011.318.

16. Olmer R, Lange A, Selzer S, Kasper C, Haverich A, Martin U, et al. Suspension culture of human pluripotent stem cells in controlled, stirred bioreactors. Tissue Eng Part C Methods. Mary Ann Liebert, Inc. 140 Huguenot Street, 3rd Floor New Rochelle, NY 10801 USA ; 2012 [cited 2019 Sep 10];18:772-84. Available from: https://www.liebertpub. com/doi/10.1089/ten.tec.2011.0717.

17. Abbasalizadeh S, Larijani MR, Samadian A, Baharvand H. Bioprocess development for mass production of size-controlled human pluripotent stem cell aggregates in stirred suspension bioreactor. Tissue Eng Part C Methods. 2012 [cited 2017 Jul 19];18:831-51. Available from: http://online. liebertpub.com/doi/abs/10.1089/ten.tec.2012.0161.

18. Wang Y, Chou B-K, Dowey S, He C, Gerecht S, Cheng L. Scalable expansion of human induced pluripotent stem cells in the defined xeno-free E8 medium under adherent and suspension culture conditions. Stem Cell Res; 2013 [cited 2019 Sep 12];11:1103-16. Available from: https://www. sciencedirect.com/science/article/pii/S1873506113001116.

19. Elanzew A, Sommer A, Pusch-Klein A, Brüstle O, Haupt S. A reproducible and versatile system for the dynamic expansion of human pluripotent stem cells in suspension. Biotechnol J. 2015 [cited 2019 Sep 12];10:1589-99. Available from: http://doi.wiley.com/10.1002/biot.201400757.

20. Haraguchi Y, Matsuura K, Shimizu T, Yamato M, Okano T. Simple suspension culture system of human iPS cells maintaining their pluripotency for cardiac cell sheet engineering. J Tissue Eng Regen Med; 2015 [cited 2019 Sep 12];9: 1363-75. Available from: http://doi.wiley.com/10.1002/term.1761.

21. Badenes SM, Fernandes TG, Rodrigues CAV, Diogo MM, Cabral JMS. Microcarrier-based platforms for in vitro expansion and differentiation of human pluripotent stem cells in bioreactor culture systems. J Biotechnol; 2016 [cited 2019 Sep 12];234:71-82. Available from: https://www. sciencedirect.com/science/article/pii/S016816561631433X.

22. Chen KG, Mallon BS, Hamilton RS, Kozhich OA, Park K, Hoeppner DJ, et al. Non-colony type monolayer culture of human embryonic stem cells. Stem Cell Res. 2012;9:237-48.

23. Kunova M, Matulka K, Eiselleova L, Salykin A, Kubikova I, Kyrylenko S, et al. Adaptation to robust monolayer expansion produces human pluripotent stem cells with improved viability. Stem Cells Transl Med. 2013;2:246-54.

24. Gerecht-Nir S, Cohen S, Itskovitz-Eldor J. Bioreactor cultivation enhances the efficiency of human embryoid body (hEB) formation and differentiation. Biotechnol Bioeng. 2004;86:493-502.

25. Cameron C, Hu W-S, Kaufman DS. Improved development of human embryonic stem cell-derived embryoid bodies by stirred vessel cultivation. Biotechnol Bioeng. 2006;5:938-48.

26. Yirme G, Amit M, Laevsky I, Osenberg S, Itskovitz-Eldor J. Establishing a dynamic process for the formation, propagation, and differentiation of human embryoid bodies. Stem Cells Dev. 2008 [cited 2018 Aug 23];17: 1227-42. Available from: www.liebertpub.com.

27. Lock LT, Tzanakakis ES. Expansion and differentiation of human embryonic stem cells to endoderm progeny in a microcarrier stirred-suspension culture. Tissue Eng Part A. 2009;15:2051-63 Available from: http://www. liebertonline.com/doi/abs/10.1089/ten.tea.2008.0455.

28. Amit M, Chebath J, Margulets V, Laevsky I, Miropolsky Y, Shariki K, et al. Suspension culture of undifferentiated human embryonic and induced pluripotent stem cells. Stem Cell Rev Reports. 2010 [cited 2018 Jun 11];6: 248-59. Available from: http://www.ncbi.n/m.nih.gov/pubmed/20431964.

29. Chen AKL, Chen X, Choo ABH, Reuveny S, Oh SKW. Critical microcarrier properties affecting the expansion of undifferentiated human embryonic stem cells. Stem Cell Res. 2011;7:97-111.

30. Heng BC, Li J, Chen AKL, Reuveny S, Cool SM, Birch WR, et al. Translating human embryonic stem cells from 2-dimensional to 3-dimensional cultures in a defined medium on laminin- and vitronectin-coated surfaces. Stem Cells Dev. 2012;21:1701-15.

31. Stolberg S, McCloskey KE. Can shear stress direct stem cell fate? Biotechnol Prog. 2009 [cited 2017 Jul 19];25:10-9. Available from: http://doi.wiley.com/1 $0.1002 /$ btpr.124

32. Abecasis B, Aguiar T, Arnault É, Costa R, Gomes-Alves P, Aspegren A, et al. Expansion of $3 D$ human induced pluripotent stem cell aggregates in bioreactors: bioprocess intensification and scaling-up approaches. J Biotechnol; 2017 [cited 2019 Sep 10];246:81-93. Available from: https:// www.sciencedirect.com/science/article/pii/S0168165617300214.

33. Borys BS, Le A, Roberts EL, Dang T, Rohani L, Hsu CYM, et al. Using computational fluid dynamics (CFD) modeling to understand murine embryonic stem cell aggregate size and pluripotency distributions in stirred suspension bioreactors. J Biotechnol. 2019;304:16-27.

34. Sousa MFQ, Silva MM, Giroux D, Hashimura $Y$, Wesselschmidt R, Lee B, et al. Production of oncolytic adenovirus and human mesenchymal stem cells in a single-use, vertical-wheel bioreactor system: impact of bioreactor design on performance of microcarrier-based cell culture processes. Biotechnol Prog 2015 [cited 2019 Sep 10];31:1600-12. Available from: http://doi.wiley. com/10.1002/btpr.2158.

35. Rodrigues CA, Silva TP, Nogueira DE, Fernandes TG, Hashimura $Y$, Wesselschmidt $R$, et al. Scalable culture of human induced pluripotent cells on microcarriers under xeno-free conditions using single-use vertical-wheel ${ }^{\text {TM }}$ bioreactors. J Chem Technol Biotechnol; 2018 [cited 2019 Sep 10];93:3597-606. Available from: http://doi.wiley.com/10.1 $002 / j c t b .5738$.

36. Croughan MS, Giroux D, Fang D, Lee B. Novel single-use bioreactors for scale-up of anchorage-dependent cell manufacturing for cell therapies. Stem Cell Manuf. 2016 [cited 2019 Sep 10]. p. 105-39. Available from: https://www.sciencedirect.com/science/article/pii/B9780444632654000054.

37. Kaiser S, Löffelholz C. CFD for characterizing standard and single-use stirred cell culture bioreactors. Comput Fluid Dyn Technol Appl. 2011:97-122.

38. Kelly WJ. Using computational fluid dynamics to characterize and improve bioreactor performance. Biotechnol Appl Biochem. 2008:49:225-38.

39. Nienow AW, Rielly CD, Brosnan K, Bargh N, Lee K, Coopman K, et al. The physical characterisation of a microscale parallel bioreactor platform with an industrial CHO cell line expressing an IgG4. Biochem Eng J. 2013;76:25-36.

40. Sucosky P, Osorio DF, Brown JB, Neitzel GP. Fluid mechanics of a spinnerflask bioreactor. Biotechnol Bioeng. 2004;85:34-46.

41. Borys BS, So T, Colter J, Dang T, Roberts EL, Revay T, et al. Optimized serial expansion of human induced pluripotent stem cells using low density inoculation to generate clinically relevant quantities in vertical-wheel bioreactors. Stem Cells Transl Med. 2020:19-0406.

42. Rohani L, Machiraju P, Sabouny R, Meng G, Liu S, Zhao T, et al. Reversible mitochondrial fragmentation in iPSC-derived cardiomyocytes from children with DCMA, a mitochondrial cardiomyopathy. Can J Cardiol. 2020;36:554-63.

43. Heidariyan Z, Ghanian MH, Ashjari M, Farzaneh Z, Najarasl M, Rezaei Larijani $M$, et al. Efficient and cost-effective generation of hepatocyte-like cells through microparticle-mediated delivery of growth factors in a 3D culture of human pluripotent stem cells. Biomaterials. 2018;159:174-88.

44. Lipsitz YY, Woodford C, Yin T, Hanna JH, Zandstra PW. Modulating cell state to enhance suspension expansion of human pluripotent stem cells. Proc Natl Acad Sci U S A. 2018;115:6369-74.

45. van Winkle A, Gates I, Kallos M. Mass transfer limitations in embryoid bodies during human embryonic stem cell differentiation. Cells Tissues Organs. 2012;196:34-7.

46. Veraitch FS, Scott R, Wong JW, Lye GJ, Mason C. The impact of manual processing on the expansion and directed differentiation of embryonic stem cells. Biotechnol Bioeng. 2008 [cited 2020 Feb 18];99:1216-29. Available from: http://www.ncbi.n/m.nih.gov/pubmed/17929326. 
47. Kino-Oka M, Chowdhury SR, Muneyuki Y, Manabe M, Saito A, Sawa Y, et al. Automating the expansion process of human skeletal muscle myoblasts with suppression of myotube formation. Tissue Eng - Part C Methods. 2009; 15:717-28.

48. Ker DFE, Weiss LE, Junkers SN, Chen M, Yin Z, Sandbothe MF, et al. An engineered approach to stem cell culture: automating the decision process for real-time adaptive subculture of stem cells. PLoS One. 2011 [cited 2020 Feb 18];6:e27672. Available from: http://www.ncbi.nlm.nih.gov/ pubmed/22110715.

49. Boheler KR. Pluripotency of human embryonic and induced pluripotent stem cells for cardiac and vascular regeneration. Thromb Haemost. Schattauer $\mathrm{GmbH} ; 2010$ [cited 2020 Feb 18];104:23-9. Available from: http:// www.thieme-connect.de/DOI/DOI?10.1160/TH09-07-0507.

50. Soares FAC, Chandra A, Thomas RJ, Pedersen RA, Vallier L, Williams DJ. Investigating the feasibility of scale up and automation of human induced pluripotent stem cells cultured in aggregates in feeder free conditions. J Biotechnol. 2014;173:53-8.

51. Liu N, Zang R, Yang S-T, Li Y. Stem cell engineering in bioreactors for largescale bioprocessing. Eng Life Sci; 2014 [cited 2019 Aug 20];14:4-15. Available from: http://doi.wiley.com/10.1002/elsc.201300013.

52. Kehoe DE, Jing D, Lock LT, Tzanakakis ES. Scalable stirred-suspension bioreactor culture of human pluripotent stem cells. Tissue Eng Part A. 2010 [cited 2017 Jul 19];16:405-21. Available from: http://www.liebertonline.com/ doi/abs/10.1089/ten.tea.2009.0454.

53. Narsinh KH, Sun N, Sanchez-Freire V, Lee AS, Almeida P, Hu S, et al. Single cell transcriptional profiling reveals heterogeneity of human induced pluripotent stem cells. J Clin Invest. 2011;121:1217-21.

54. Borys BS, Roberts EL, Le A, Kallos MS. Scale-up of embryonic stem cell aggregate stirred suspension bioreactor culture enabled by computational fluid dynamics modeling. Biochem Eng J.; 2018 [cited 2019 Apr 23];133:15767. Available from: https://www.sciencedirect.com/science/article/pii/S136 9703X18300561.

55. Haraguchi Y, Matsuura K, Shimizu T, Yamato M, Okano T. Simple suspension culture system of human iPS cells maintaining their pluripotency for cardiac cell sheet engineering. J Tissue Eng Regen Med; 2015 [cited 2019 Sep 10];9: 1363-75. Available from: http://doi.wiley.com/10.1002/term.1761.

56. Kwok CK, Ueda Y, Kadari A, Günther K, Ergün S, Heron A, et al. Scalable stirred suspension culture for the generation of billions of human induced pluripotent stem cells using single-use bioreactors. J Tissue Eng Regen Med; 2018 [cited 2019 Sep 12];12:e1076-87. Available from: http://doi.wiley.com/1 0.1002/term.2435.

57. Amps K, Andrews PW, Anyfantis G, Armstrong L, Avery S, Baharvand H, et al. Screening ethnically diverse human embryonic stem cells identifies a chromosome 20 minimal amplicon conferring growth advantage. Nat Biotechnol. 2011;29:1132-44.

58. Nie Y, Walsh P, Clarke DL, Rowley JA, Fellner T. Scalable passaging of adherent human pluripotent stem cells. PLoS One. 2014;9.

59. Mohr JC, Zhang J, Azarin SM, Soerens AG, de Pablo JJ, Thomson JA, et al. The microwell control of embryoid body size in order to regulate cardiac differentiation of human embryonic stem cells. Biomaterials. 2010 [cited 2020 Feb 19];31:1885-93. Available from: http://www.ncbi.nlm.nih.gov/ pubmed/19945747.

60. Messana JM, Hwang NS, Coburn J, Elisseeff JH, Zhang Z. Size of the embryoid body influences chondrogenesis of mouse embryonic stem cells. J Tissue Eng Regen Med. 2008 [cited 2020 Feb 19];2:499-506. Available from: http://www.ncbi.n/m.nih.gov/pubmed/18956411.

61. Kropp C, Kempf H, Halloin C, Robles-Diaz D, Franke A, Scheper T, et al. Impact of feeding strategies on the scalable expansion of human pluripotent stem cells in single-use stirred tank bioreactors. Stem Cells Transl Med; 2016 [cited 2019 Jun 7];5:1289-301. Available from: http://www. ncbi.nlm.nih.gov/pubmed/27369897.

62. Stover $\mathrm{AE}$, Schwartz PH. Adaptation of human pluripotent stem cells to feeder-free conditions in chemically defined medium with enzymatic singlecell passaging. Methods Mol Biol. 2011;767:137-46.

63. Roberts EL, Dang T, Lepage SIM, Alizadeh AH, Walsh T, Koch TG, et al. Improved expansion of equine cord blood derived mesenchymal stromal cells by using microcarriers in stirred suspension bioreactors. J Biol Eng. 2019 [cited 2020 Mar 3];13:25. Available from: https://jbioleng. biomedcentral.com/articles/10.1186/s13036-019-0153-8.

64. Cunha B, Aguiar T, Carvalho SB, Silva MM, Gomes RA, Carrondo MJT, et al. Bioprocess integration for human mesenchymal stem cells: from up to downstream processing scale-up to cell proteome characterization. J Biotechnol 2017 [cited 2020 Mar 3];248:87-98. Available from: http://www. ncbi.nlm.nih.gov/pubmed/28174039.

65. Heathman TRJ, Glyn VAM, Picken A, Rafiq QA, Coopman K, Nienow AW, et al. Expansion, harvest and cryopreservation of human mesenchymal stem cells in a serum-free microcarrier process. Biotechnol Bioeng. 2015;112: 1696-707.

66. Nienow AW, Rafiq QA, Coopman K, Hewitt CJ. A potentially scalable method for the harvesting of hMSCs from microcarriers. Biochem Eng J. 2014;85:79-88.

67. Fernandes AM, Fernandes TG, Diogo MM, da Silva CL, Henrique D, Cabral JMS. Mouse embryonic stem cell expansion in a microcarrier-based stirred culture system. J Biotechnol. 2007 [cited 2020 Feb 18];132:227-36. Available from: http://www.ncbi.nlm.nih.gov/pubmed/17644203.

68. King JA, Miller WM. Bioreactor development for stem cell expansion and controlled differentiation. Curr Opin Chem Biol. 2007;11:394-8.

69. Abranches E, Bekman E, Henrique D, Cabral JMS. Expansion of mouse embryonic stem cells on microcarriers. Biotechnol Bioeng. Wiley-Blackwell; 2007 [cited 2018 Jun 9];96:1211-21. Available from: http://doi.wiley.com/10.1 002/bit.21191.

70. Borys BS, So T, Roberts EL, Ferrie L, Larijani L, Abraham B, et al. Large-scale expansion of feeder-free mouse embryonic stem cells serially passaged in stirred suspension bioreactors at low inoculation densities directly from cryopreservation. Biotechnol Bioeng. John Wiley and Sons Inc.; 2020 [cited 2020 Mar 3]; Available from: http://www.ncbi.nlm.nih.gov/pubmed/31960947.

71. Phillips BW, Horne R, Lay TS, Rust WL, Teck TT, Crook JM. Attachment and growth of human embryonic stem cells on microcarriers. J Biotechnol. Elsevier. 2008;138:24-32.

\section{Publisher's Note}

Springer Nature remains neutral with regard to jurisdictional claims in published maps and institutional affiliations.

Ready to submit your research? Choose BMC and benefit from:

- fast, convenient online submission

- thorough peer review by experienced researchers in your field

- rapid publication on acceptance

- support for research data, including large and complex data types

- gold Open Access which fosters wider collaboration and increased citations

- maximum visibility for your research: over $100 \mathrm{M}$ website views per year

At BMC, research is always in progress.

Learn more biomedcentral.com/submissions 